\title{
COSTRICE - three model online coupling using OASIS: problems and solutions
}

\author{
H. T. M. Ho, B. Rockel, H. Kapitza, B. Geyer, and E. Meyer
}

Institute for Coastal Research, Helmholtz-Zentrum Geesthacht, Geesthacht, Germany

Received: 1 October 2012 - Accepted: 3 October 2012 - Published: 17 October 2012

Correspondence to: H. T. M. Ho (ha.ho@ hzg.de)

Published by Copernicus Publications on behalf of the European Geosciences Union.

\section{COSTRICE - three model online coupling using \\ OASIS}

H. T. M. Ho et al.

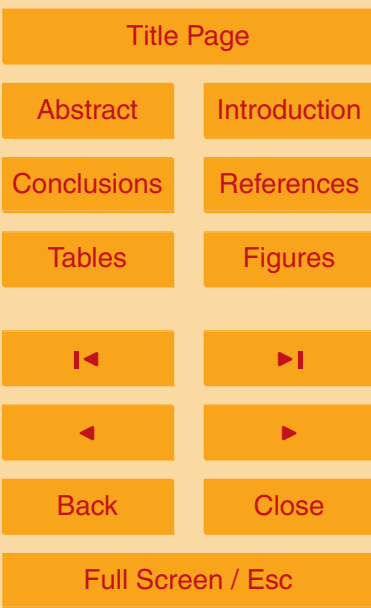

Printer-friendly Version

Interactive Discussion 


\section{Abstract}

The coupled system COSTRICE is developed for the first time in order to reproduce the interactions and feedbacks between atmosphere, ocean and sea-ice in a two-way online coupled model system containing three component models for regional climate 5 simulations over Baltic Sea and North Sea regions. The regional climate model CCLM ${ }^{1}$ is coupled to the regional ocean model TRIMNP ${ }^{1}$ and the sea ice model CICE $^{1}$ via the coupler OASIS3. In this study, CCLM is setup with a horizontal grid mesh size of $50 \mathrm{~km}$ and 32 vertical atmosphere layers and driven by the 6-h ERA-interim reanalysis data as initial and boundary conditions. TRIMNP is setup with a horizontal grid mesh size of $12.8 \mathrm{~km}$ and 50 vertical ocean levels. CICE calculates ice in 5 categories and runs with the same horizontal resolution as TRIMNP but only over the Baltic Sea and the Kattegat Bay of the North Sea. In a two-way online coupling process, CCLM is linked to TRIMNP through sea surface temperature (SST) as lower boundary condition every $3 \mathrm{~h}$ and TRIMNP is driven by $1-\mathrm{h}$ atmospheric state variables and fluxes of CCLM. The data exchange processes between TRIMNP and CICE as well as from CCLM to CICE take place with an interval of $3 \mathrm{~h}$. The coupled model is applied in a study for climate simulations over Baltic Sea and North Sea regions in 1997. The coupled system is set up to run in parallel on the super computing system IBM-power 6 at the German Climate Computing Center (DKRZ).

\section{Introduction}

This paper introduces a first time development of a two-way online coupled system from three models of atmosphere, ocean and sea ice (CCLM, TRIMNP and CICE, respectively) using the coupler OASIS version 3 (Fig. 1) for regional climate simulations. This study provides an overview of the coupling mechanism in term of online (i.e. all three component models run in parallel) and two-way interactions and feedbacks (i.e.

\footnotetext{
${ }^{1}$ See Table A1.
}

GMDD

$5,3261-3310,2012$

COSTRICE - three model online coupling using

OASIS

H. T. M. Ho et al.

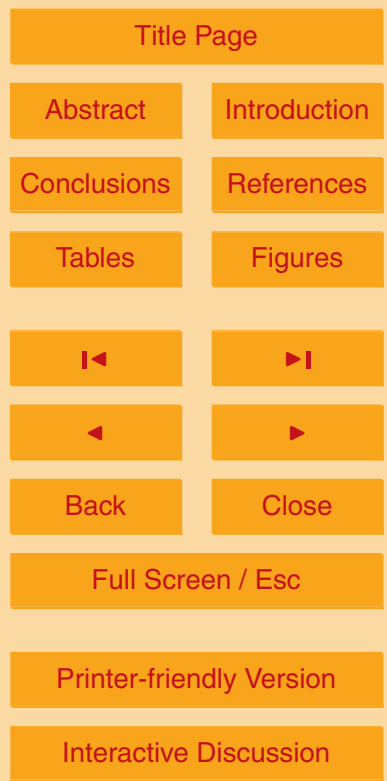

Interactive Discussion 
each pair of them exchanges data at every coupling time step). Following the coupling mechanism, source codes of component models have to be adapted and libraries of the coupler OASIS are used to link the three models together. The paper also addresses the basis to define coupled fields and the coupling time while exchanging data.

5 Atmosphere, ocean and sea ice are fundamental components of the climate system. The state of the art global (GCMs) and regional climate models (RCMs) have been trying to simulate as much as possible about their structures, interactions and feedbacks. Specific features of the components of the atmosphere, the ocean and the sea ice are treated differently in the models. The most challenging task is to reproduce the inter10 action processes at the interface of those components. Simulation of the interactions does not only require high performance computing but also suitable observation data for their respective evaluation. The former requirement was a great challenge in the past while nowadays super computers are available and applied at many laboratories, but the latter is still a big issue up to date. For example, observed data of momentum 15 and heat fluxes over the ocean may only be found in some projects for some areas (e.g. TOGA COARE, Soloviev and Lukas, 1997; Webster et al., 1996; BOMEX, Delnore, 1972), and the diurnal warming profiles (Halpern and Reed, 1976; Gentemann et al., 2009). Rutgersson (2000) and Rutgersson et al. (2001, 2005, 2007) focused on observed sea surface temperature, wind speed and direction, momentum and heat fluxes at the station Oestergarnsholm in the Baltic Proper to validate the simulation skill of the RCM HIRHAM. The respective time series are available mainly from May 1995 to February 1997 and they are sometimes interrupted but they provide useful information of air-sea interaction for coupling studies over this area.

Air-sea interactions over the North Atlantic and Pacific oceans are investigated by 25 Zhang (1996) using observed data. The study showed that in winter the dominant process of air-sea interaction for both oceans is the atmospheric forcing of the ocean through modulating the latent and sensible heat fluxes. Kirtman and Vecchi (2011) also pointed out that SST anomalies can induce anomalous convection through surface evaporation and low-level moisture convergence. In turn, the anomalous atmospheric
GMDD

$5,3261-3310,2012$

COSTRICE - three model online

coupling using

OASIS

H. T. M. Ho et al.

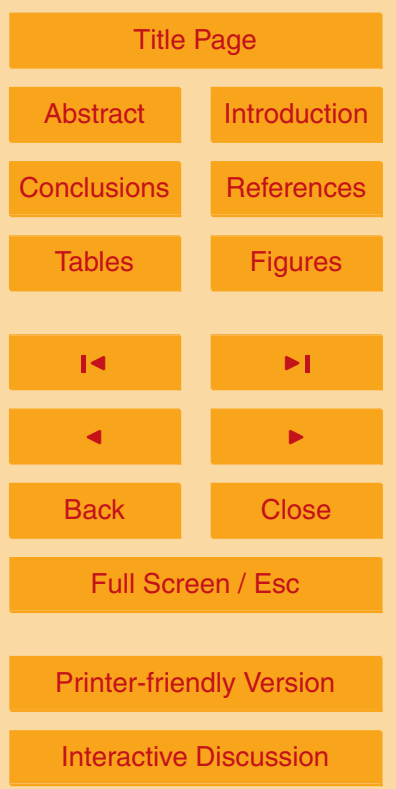


convection can change the SST through cloud-radiation and wind-evaporation effects as well as wind-induced oceanic mixing and upwelling. As air-sea interactions play an important role in keeping the whole climate system in equilibrium it's necessary to take air-sea interaction into account in a climate model, or in other words to couple different 5 numerical component models in one model system.

To date, "coupling" has not been a new problem but is frequently applied in climate modeling research. The components of coupling can be atmosphere, ocean, sea ice, soil, chemistry, waves, etc. There are many studies on coupled climate models at the global scale (e.g. Manabe and Bryan, 1969, 1979; Washington et al., 1980; Neelin 10 et al., 1994, Dai, 2006, Taylor et al., 2009, 2012) or at the regional scale for limited areas (e.g. Gustafsson et al., 1998; Raible et al., 2001; Sun and Hansen, 2003; Dorn et al., 2007; Artale et al., 2009; Davin et al., 2011; Elizalde and Jacob, 2012). For the Baltic region, the history of coupling up to the 2000s was presented in Döscher et al. (2002) with the citations for previous studies such as by Gustafsson et al. (1998), 15 Hagedorn et al. (2000), Rummukainen et al. (2001), Schrum et al. (2001). They are followed by other studies like those by Omstedt and Rutgersson (2000), Jacob et al. (2001), Döscher et al. (2002), Schrum et al. (2003), Meier et al. (2003, 2004), Lehmann et al. (2004), Bennartz et al. (2009). Those studies focused on this region because the Baltic Sea area is subject to global influences, while the climate of the Baltic Sea basin is merged by continental and maritime climates due to the geographical location, variable orography, and land-sea contrasts (HELCOM, 2007). Gustafsson et al. (1998) provided some special examples of "changing ice boundaries" in winter and "changing SSTs" in summer over the Baltic catchment in 1993-1995 to prove that coupling is necessary in both numerical weather prediction and climate simulations for this region as the interactions and feedbacks among climate components may amplify errors in the whole system if one of them is represented too unrealistically. The North Sea was also focused in some studies such as by Rodenhuis (1978) and Pohlmann (1996), and it is often considered together with the Baltic Sea (Woth et al., 2006; Schrum et al., 2003).
GMDD

$5,3261-3310,2012$

COSTRICE - three model online coupling using OASIS

H. T. M. Ho et al.

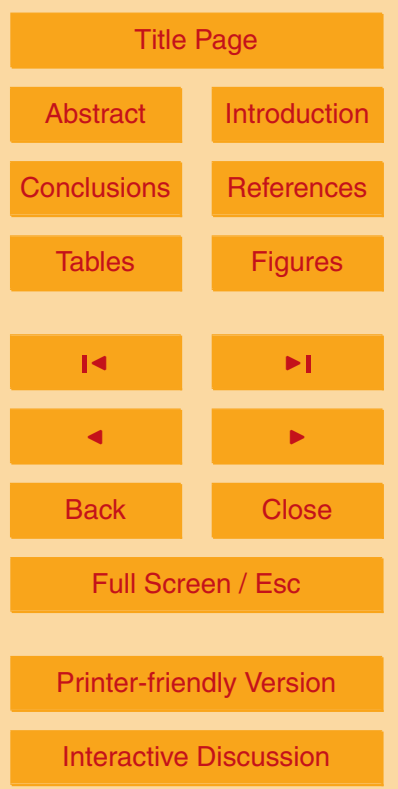


Offline or online coupling systems are built depending on the considered problems. A simple example of an offline coupling is to run the atmosphere model for a month and then using its output as the input for the ocean model. In turn, the ocean model provides SST to run the atmosphere model once again for that month. However, this 5 method costs a lot of computing time and is just useful to see how well the ocean model reproduces SST and how the SST influences the results of the atmosphere model. Another but similar way to do coupling is to run the atmosphere model for one day and to send the output to the ocean model, which in turn runs and pays back SST to the atmosphere model at the end of day so that it can use this SST for simulating 10 the next day (Tian et al., 2012). This process can be called "semi-offline" as the two models don't run in parallel but SST is updated once a day for the atmosphere model. The online coupling is defined as a process in which two or more models run in parallel and exchange data more often to take interactions and feedbacks into account. Our study is focusing on this process.

15 The online coupling may operate in a way of source code combination or another way of data transfer. The former method requires software interfaces (e.g. Gustafsson et al., 1998). The latter only needs to exchange the data so it is more flexible and source code changes are not necessary. However, before coupler programs became popular, data were transferred via files (e.g. Schrum et al., 2003) and that process usually needs a huge storage and a long computing time. By using a coupler like OASIS, the complex technical problems arising from an all-in-one code are avoided (Döscher et al., 2002) and the coupler helps to exchange data directly among component models and performs the necessary interpolation between different model grids. In case component models have the same grid, data is passed directly from the source grid to the target one. The advantage of the coupler is even more highlighted when more than two models are coupled together. In our case, in winter time, sea ice is created over the Baltic Sea but the chosen ocean model doesn't take sea ice calculation into account. That's why beside the atmosphere and the ocean model, a sea ice model has to be coupled to the RCM system. Moreover, an individual sea ice model coupled in
GMDD

$5,3261-3310,2012$

COSTRICE - three model online

coupling using

OASIS

H. T. M. Ho et al.

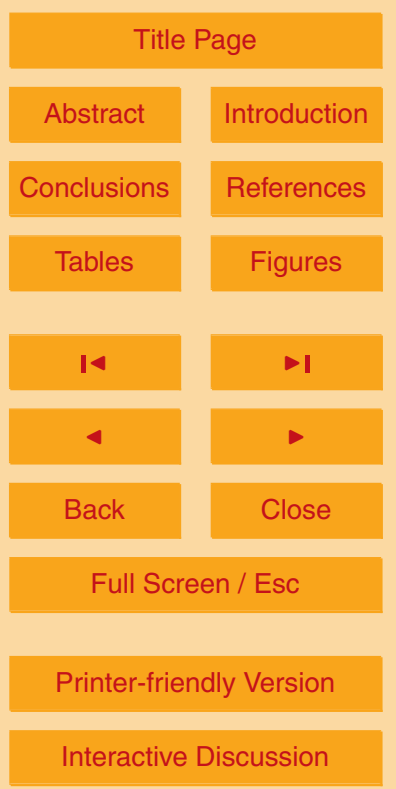


the system may reproduce the ice formation, retreat and shifting more adequate than a simple sea ice parameterization scheme such as often used in ocean models.

An important question that is often considered with less attention is what the suitable coupling frequency should be. A unique answer can hardly be found as it depends on 5 a variety of conditions like climatic region, season, physical processes, used models, etc. But this should not be the reason for choosing an arbitrary coupling time. In addition, the definition of a suitable coupling time in a coupled system shouldn't be mixed up with the equilibrium time. For example, the equilibrium time of the atmosphere boundary or the snow and surface ice layer is $24 \mathrm{~h}$ (McGuffie and Henderson-Sellers, 1997).

10 This doesn't mean that the status of the atmosphere only changes significantly after a day but hour-to-hour, which causes "weather". The fast changes of surface wind as a forcing may cause or intensify the wind-driven waves on the sea surface or lead to a well mixing of the heat generated in the upper ocean due to the absorption of solar radiation. In turn, the response or feedback from the ocean to the atmosphere is via 15 momentum, heat, water vapor and gas fluxes which mostly depend on SST. The ocean skin temperature may change significantly in periods of an hour or less (Gentemann and Minnett, 2008; Minnett, 2012), which is different from the equilibrium time of the ocean mixed layer in the order of months to years (McGuffie and Henderson-Sellers, 1997). McGuffie and Henderson-Sellers (2005) also supposed that the coupling and feedbacks amongst processes within the climate system components is responsible for the myriad of variations in this climate system spectrum. That's why component models should be coupled more often than the equilibrium time of the climate components to adequately capture its different characteristic of variability. As a practical proof for this comment, Bernie et al. (2008) used the coupled GCM model HadOPA which consists of Hadley centre Atmospheric Model version 3 (HadAM3) developed at the UK Met Office (Pope et al., 2001), coupled to the French ocean GCM OPA (Madec et al., 1998) via OASIS3 to examine the impact of the resolving the diurnal cycle in the upper ocean and of ocean-atmosphere interactions on the diurnal to seasonal variability of the coupled system. Following Bernie et al. (2008), Terray et al. (2012) and some

\section{GMDD}

$5,3261-3310,2012$

COSTRICE - three model online

coupling using

OASIS

H. T. M. Ho et al.

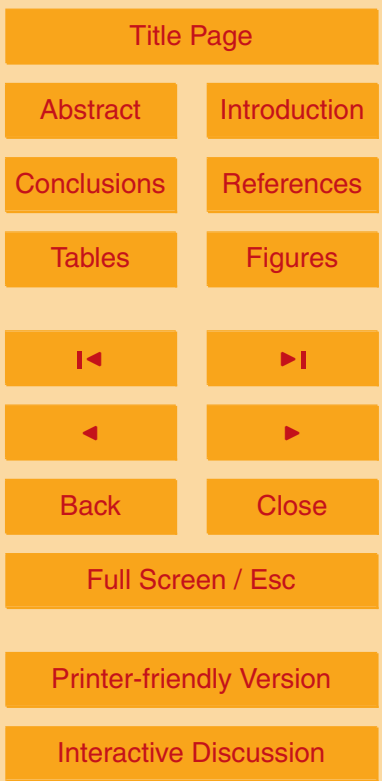


others studies like by Danabasoglu et al. (2006) and Ham et al. (2010) set up their experiments with 1-day and 1-3h air-sea coupling and pointed out that the diurnal variations of oceanic quantities are not simulated with the 1-day air-sea coupling.

In early studies with coupled RCMs, the coupling time of $6 \mathrm{~h}$ or longer was often cho5 sen without any explanation or with a vague argument that it is at the same frequency of the updated lateral boundary conditions, for example by Artale et al. (2009) in which RegCM3 is coupled to MITgcm for climate simulations over the Mediterrean Sea. For the same region, Elizalde et al. (2010) coupled the RCM REMO to MPI-OM every $6 \mathrm{~h}$. Schrum et al. (2003) coupled REMO to HAMSOM to simulate climate over the North 10 Sea and the Baltic Sea in which data of REMO is passed to HAMSOM every $6 \mathrm{~h}$ and daily SST from HAMSOM is given back to REMO. The first RCM coupling study was conducted by Gustafsson (1998) who coupled the regional atmosphere model HIRLAM to the ocean model of Sweden's Meteorological and Hydrological Institute (SMHI) with the coupling time of $3 \mathrm{~h}$ from atmosphere to ocean and 1 day from ocean to atmosphere. Meier et al. $(2003,2004)$ and Döscher et al. (2002) applied the coupled system RCAO (using the atmosphere RCM RCA and the ocean model RCO coupled by OA$\mathrm{SIS}$ ) and set the coupling time to $3 \mathrm{~h}$ to represent the diurnal cycles. Nevertheless, $6 \mathrm{~h}$ coupling may already describe the diurnal cycle (Sheffield, 2006). Exceptionally, Bennartz et al. (2009) applied the model system BALTIMOS (BALTEX) for the Baltic Sea region in winter 2002/2003 in which the component models are coupled hourly by the exchange of fluxes and state variables. However, this research implemented a direct coupling without a coupler and hourly coupling may be due to the output writing time period. Thus, the question of the optimal coupling time is still open. In this paper, using long term simulations of stand-alone versions of CCLM and TRIMNP, we are trying to answer it at least for the atmosphere-ocean-sea ice coupling over the Baltic Sea.

Another coupling problem is the adequate selection of variables that are exchanged amongst the component models. In reality, there are momentum, heat, water, and gas exchanges at the air-sea interface (Rothrock et al., 1999). However, in the present study gas exchange is not taken into account but the others are. The heat, humidity
GMDD

$5,3261-3310,2012$

COSTRICE - three model online

coupling using

OASIS

H. T. M. Ho et al.

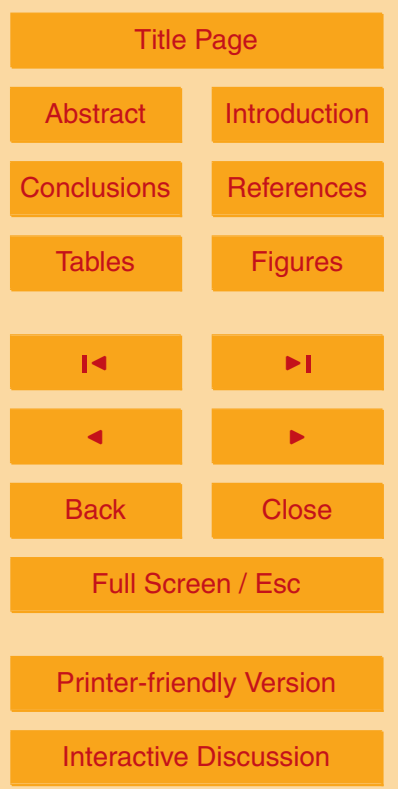


and momentum fluxes are passed from atmosphere to ocean and sea ice or transferred between ocean and sea ice. The feedback of ocean to atmosphere is presented via SST because SST plays an important role in the upper oceans heat content, and regulates climate. Zhang (1996) supposed that over the North Atlantic, the simple ther5 modynamic equilibration is dominant after the author found out the strong correlation between SST anomalies and hemispheric-mean lower tropospheric temperature. Near by, the climate of the Baltic Sea is influenced by major air pressure systems, particularly the North Atlantic Oscillation (NAO) during wintertime, which affects the atmospheric circulation and precipitation in the Baltic Sea basin (HELCOM, 2007). Moreover, due to 10 ice conditions in the Baltic Sea, a strong relationship has been reported between winter sea-surface salinity and temperature anomalies and climatic indicators. Owing to the geographical location, variable orography, and land-sea contrasts, in the long-term mean, the Baltic Sea is almost thermodynamically closed. Thus, annually the dominating fluxes are the sensible heat, the latent heat, the net longwave radiation, the solar 15 radiation to the open water, and the heat flux between water and ice (Omstedt and Rutgersson, 2000). In the water and energy cycle studies for the BALTEX program, the response of the salinity and heat content of the Baltic are important parameters to study when evaluating and improving atmosphere, ocean and river runoff models (Meier and Döscher, 2002).

20 The main purpose of this study is to reproduce the interactions and feedbacks in the climate system via couplings to improve the climate simulation over Baltic Sea and North Sea regions. The regional ocean model with a resolution of several kilometres used in the coupled system may represent more details and hence provides better SST to the atmosphere model than a global ocean model or reanalysis data. The resolution of reanalysis data such as ERA-interim is not fine enough to adequately represent SST over the considered region, especially near the coastlines of the Baltic Sea and the North Sea. Hence, using the coupled system may improve the simulated SST and heat fluxes, and then improve the regional climate simulation over the considered regions.
GMDD

$5,3261-3310,2012$

COSTRICE - three model online

coupling using

OASIS

H. T. M. Ho et al.

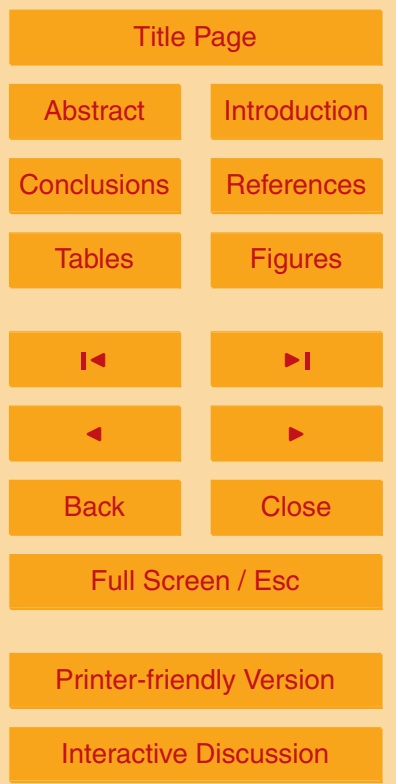


Models and experiments are presented in Sect. 2. Section 3 analyses and discusses the main results. Some conclusions and suggestions are presented in Sect. 4.

\section{Models and experiments}

\subsection{Models}

\section{$5 \quad$ 2.1.1 Atmosphere model}

The atmospheric model used in the current study is the non-hydrostatic regional climate model CCLM (Consortium for Small-scale Modeling model in CLimate Mode, Rockel et al., 2008) version cosmo_4.8_clm11 developed by COSMO (http://www. cosmo-model.org) and the CLM-community (http://www.clm-community.eu). CCLM is based on the primitive thermo-hydrodynamical equations describing compressible flow in a moist atmosphere. The model equations are formulated in rotated geographical coordinates and a generalized terrain following height coordinate. A variety of physical processes (e.g. vertical radiation fluxes, vertical turbulent mixing, moisture convection, etc.) are taken into account by parameterization schemes. CCLM is driven by different lateral boundary conditions from $6 \mathrm{~h}$ NCEP, ERA40 or ERA-interim reanalysis data sets using Davies relaxation (Davies, 1976) or spectral nudging (Davies and Tunner, 1977; von Storch et al., 2000). Source code of CCLM is written in FORTRAN90 and uses the standard MPI library for parallel runs. A list of published papers using CCLM is available on the web page of the CLM-community.

\subsubsection{Ocean model}

The ocean model TRIMNP used for the coupled system is the "Nested and Parallel" version of the non-hydrostatic regional ocean model developed at HelmholtzZentrum Geesthacht, Germany, on the basis of the TRIM3D (Tidal Residual and Intertidal Mudflat Simulations in 3 Dimensions) model of University of Trento, Italy
GMDD

$5,3261-3310,2012$

COSTRICE - three model online coupling using

OASIS

H. T. M. Ho et al.

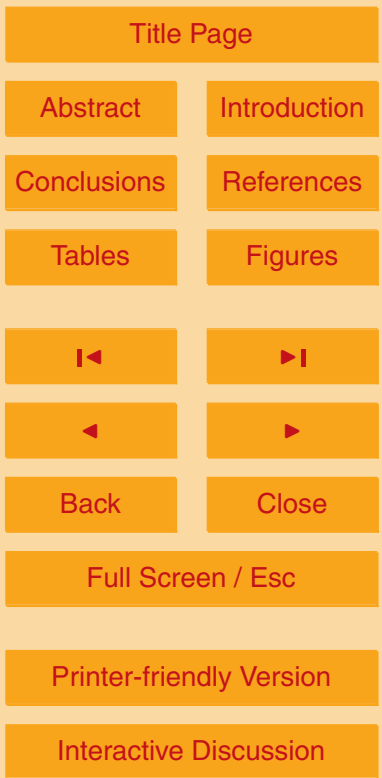

Interactive Discussion 
(Casulli and Cattani, 1994). TRIMNP is based on the 3-D Navier-Stokes equations with switchable baroclinic terms and non-hydrostatic terms. TRIMNP is formulated on a cartesian Arakawa-C grid using vertical $z$-coordinates without constraints on top layer thickness. A domain decomposition with explicit message passing is taken into 5 account using the MPI-Library. The vertical turbulent mixing is parameterised on the basis of the General Ocean Turbulence Model (GOTM) (http://www.gotm.net). More details of TRIMNP can be found in Kapitza (2008) and Kapitza and Eppel (2000). The surface boundary conditions (e.g. pressure, wind, temperature, etc.) are taken from data of regional atmosphere models (such as CCLM, REMO, etc.). The bound10 ary conditions of water temperature, salinity, currents, etc. for ocean layers are from the results of FES2004 (Finite Element Solution, Lyard et al., 2006, and Lefevre et al., 2002), and from the LEVITUS94 Ocean Climatology (http://iridl.Ideo.columbia. edu/SOURCES/.LEVITUS94). Lateral boundary treatment for TRIMNP is established based on the nudging technique of Davies (1973).

\subsubsection{Sea ice model}

The sea-ice model CICE is the Los Alamos sea ice model version 4.1 from Los Alamos National Laboratory, US (http://oceans11.lanl.gov/trac/CICE). CICE is designed to be a sea ice component of global climate models, although it can also be used in standalone mode for regional sea ice simulations. It is a thermodynamic model that computes local growth rates of snow and ice due to vertical conductive, radiative and turbulent fluxes, along with snowfall. It also includes a model of ice dynamics, which predicts the velocity field of the ice pack based on a model of the material strength of the ice as well as a transport model that describes advection of the areal concentration, ice volumes and other state variables and a ridging parameterization that transfers ice among scomb, 2008). In COSTRICE, the lack of time calculation for leap years in the current TRIMNP.
GMDD

5, 3261-3310, 2012

COSTRICE - three model online coupling using OASIS

H. T. M. Ho et al.

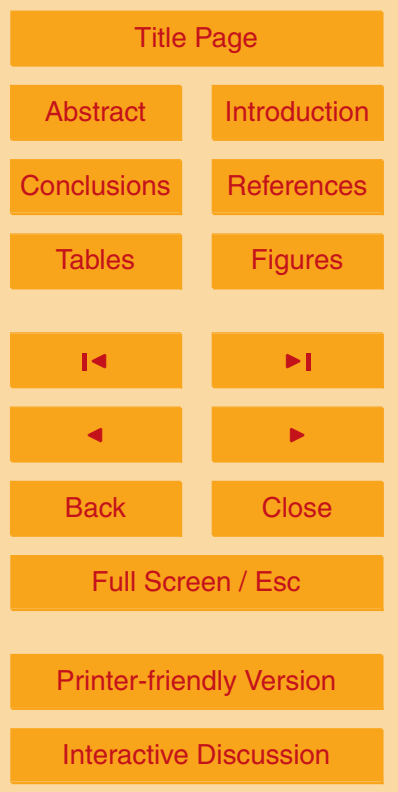

Interactive Discussion 
Table 1 presents the specifications of the three models used in our study. The configuration of the three models will be set for experiments in Sect. 2.2.

\subsubsection{Coupler}

The three models are coupled through the coupler OASIS3 (The Ocean Amosphere

5 Sea Ice Soil model version 3 of CERFACS, France) (http://oasis.enes.org). OASIS3 is a portable set of Fortran 77, Fortran 90 and $C$ routines and supports 2-D coupling fields only. The current OASIS3 version is compiled and run on NEC SX6, IBM Power4 and Linux PC cluster. OASIS3 is currently used by approximately 30 climate modelling groups in Europe, USA, Canada, Australia, India and Brazil. The main task of OASIS3 is to interpolate the fields from a source to a target grid, which usually have different resolutions and provides a mechanism for data transfer between models while they are running concurrently. The interpolation methods available in OASIS3 include the N-nearest-neighbour interpolations weighted by their distance (DISTWGT) and by their distance and a gaussian function (GAUSWGT), the bilinear (BILINEAR) and bicubic (BICUBIC) interpolations, and the 1st or 2nd order conservative remapping (CONSERV). Those techniques are offered by Los Alamos National Laboratory SCRIP 1.4 library (http://gcmd.nasa.gov/records/LANL-SCRIP.html).

\subsection{Experiments}

The coupled system is applied for climate simulations over Baltic Sea and North Sea is setup with a horizontal grid mesh size of $50 \mathrm{~km}$ and 32 vertical hybrid levels and driven by the 6-h ERA-interim reanalysis data as initial and lateral boundary conditions using Davies relaxation scheme (Davies, 1976). The running time step of CCLM is $300 \mathrm{~s}$ and CCLM's domain covers the whole Europe. The ocean model TRIMNP is setup with a horizontal grid mesh size of $12.8 \mathrm{~km}$ and 50 vertical layers to simulate the area of Baltic Sea and North Sea. The sea ice model CICE runs with the same
GMDD

$5,3261-3310,2012$

COSTRICE - three model online coupling using

OASIS

H. T. M. Ho et al.

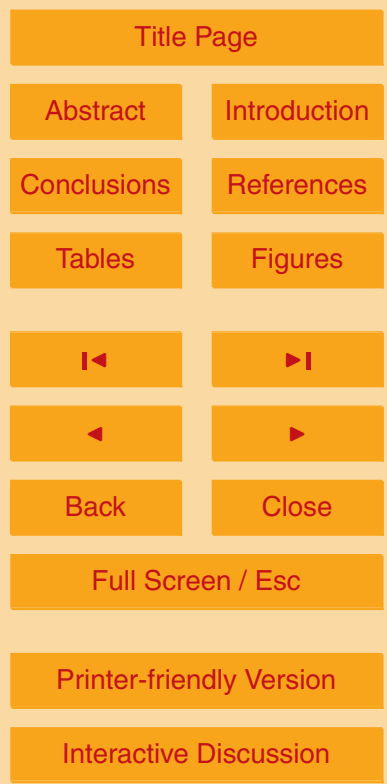


horizontal resolution as TRIMNP but only over Baltic Sea and the Kattegat Bay of North Sea. The time steps of TRIMNP and CICE are both $240 \mathrm{~s}$. For none matching areas between the two domains of CCLM and TRIMNP, the ERA-interim reanalysis SST is used (see Table 1).

5 The interpolation and data passing amongst the three models are controlled by OASIS3 at the coupling time steps of $1 \mathrm{~h}$ and $3 \mathrm{~h}$ (see Fig. 3). The list of experiments is presented in Table 2 in which the run STERva is a stand alone run where the sensible and latent heat fluxes are computed in TRIMNP based on the air surface temperature, humidity, and wind speed from CCLM. The run STERhf is also uncoupled but the heat 10 fluxes are passed from CCLM and thirdly, CPERAi is a coupled run with all fluxes including heat fluxes are passed from CCLM. The coupled system is set up to run in parallel on the super computing system IBM-power 6 at DKRZ. In the present work, we spend 3 nodes with 64 tasks per node to run the whole system in which CCLM, TRIMNP, CICE and OASIS run on 81, 98, 12 and 1 tasks, respectively (Table 1). The 15 distribution of task will change when CCLM runs with higher resolution.

As a case study the simulation time is set up from 1 January 1997 to $31 \mathrm{De}$ cember 1997. Throughout the entire time period, the three models are completely coupled. However, during the time from May to September, the skin temperature of CCLM only comes from the sea surface temperature of TRIMNP and is not affected by the sea ice from CICE because this time period mostly is the ice break-up season over Baltic Sea (Jevrejeva et al., 2004). Jevrejeva et al. (2004) used 37 time series of sea ice from observation stations in 1900-2000 to examine the evolution of ice seasons in the Baltic Sea during the 20th century and pointed that the earliest freezing time in the Baltic Sea is on some first days of October at station Kemi

in Bothnian Bay and the the latest break-up of ice season is in June, also at Kemi. But in general, the date of break-up is in April and May. The freezing and breakup dates of sea ice are also indicated in the sea ice concentration data from the daily high resolution $\left(1 / 4^{\circ} \times 1 / 4^{\circ}\right)$ NOAA Optimum Interpolation Sea Surface Temperature (OISST) version 2 (http://iridl.Ideo.columbia.edu/SOURCES/.NOAA/.NCDC/
GMDD

5, 3261-3310, 2012

COSTRICE - three model online

coupling using

OASIS

H. T. M. Ho et al.

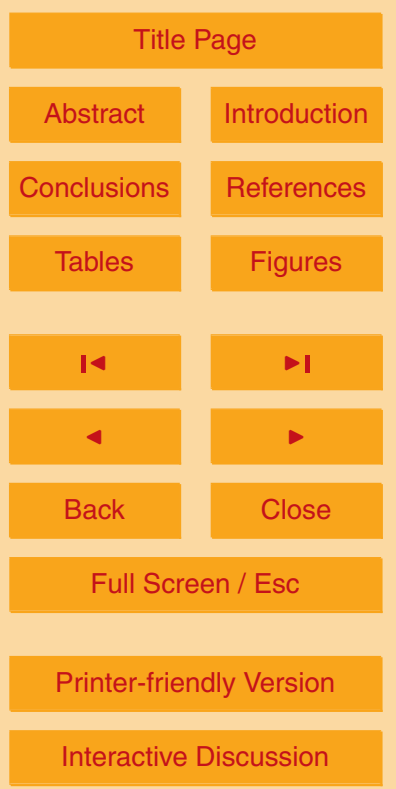


.OISST/.version2/.AVHRR/) (not shown). Consequently, these data are used along with NOAA SST data for a first evaluation of simulated SST and sea ice area from the coupled system.

\section{Problems and solutions}

5 This section focuses on the technical problems and solutions related to the coupling of the three component models (see Sect. 3.1), and the choice of the coupling time and transferred fields (see Sects. 3.2 and 3.3, respectively).

\subsection{How to do a two-way online coupling for 3 component models}

The advantage of the coupler OASIS is that the three component models keep their own executables and OASIS3 acts as an additional executable and as a communication library, the PSMILe that is linked to the models. By using OASIS, the complex technical problems arising from an all-in-one code are avoided (Döscher et al., 2002). Mostly, previous research applied OASIS for coupling an atmosphere to an ocean model that includes already a sea ice scheme. Here we introduce a detailed technique and provide some useful tips when coupling three components in one system.

First of all, you have to download and compile OASIS3 in your computer system with an awareness of the difference between running OASIS on one or more processors and of using option "oasis3_psmile" to use the PSMILe library. In our study we use one processor for OASIS3 as there's not much gain using more than one processor (discussed with Irina Fast, DKRZ) and long waiting times for the communication between processors can be avoided.

Secondly, to communicate with OASIS3 or directly with another model, a component model needs to include a few specific PSMILe calls. The grids of the three models in our study are different so the component models have to communicate via OASIS3 as they
GMDD

5, 3261-3310, 2012

COSTRICE - three model online

coupling using

OASIS

H. T. M. Ho et al.

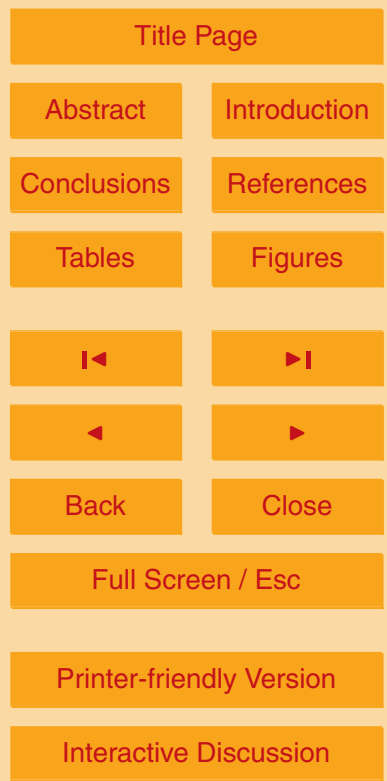


are made in the source code of CCLM while coupled (see an example in Table B1). In this example, the sending fields of CCLM are the mean sea level pressure (PMSLCCLM), the total precipitation (PRECCCLM), the rain rate (RAINCCLM) and snow rate (SNOWCCLM), while the received field is only surface temperature (T_S_CCLM). Basi5 cally, (i) CCLM is linked to TRIMNP through SST as the lower boundary condition; (ii) TRIMNP and CICE are driven by the atmospheric state variables (near surface pressure, wind, temperature, humidity, air density, cloud fraction), the lowest atmospheric level height, and fluxes (precipitation, snow, short and long wave radiation, and heat) of CCLM; and (iii) CICE requires the SST, salinity, currents, ocean surface slope, freez$10 \mathrm{ing} /$ melting potential energy from TRIMNP and in turn pays back to TRIMNP the water and ice temperature, ice concentration, fresh water flux, ice to ocean heat flux, short wave flux through ice to ocean, and ice stress components. The schematic diagram showing the data exchange can be found in Fig. 3. Here, we pass CCLM's output to TRIMNP every $1 \mathrm{~h}$ and other exchange processes are at the interval of $3 \mathrm{~h}$ (TRIMNP to 15 CCLM; CCLM exchanges with CICE; TRIMNP exchanges with CICE).

The names of variables defined in the source codes of the component models have to be the same as in the name list file of OASIS3, so-called the "namcouple". Figure 4 shows an example of the variable names that are defined and then announced by the "prism_def_var_proto" call of OASIS3 in the source code of the three models (see Table B1). Another library of OASIS3 "prism_def_partition_proto" is also used to define the transformation how the fields are exchanged by slave processors or by only the master processor. OASIS3 PSMILe supports in particular parallel communication between a parallel component model and the OASIS3 main program is based on Message Passing Interface (MPI) and file I/O is using the MPP IO library from GFDL (Valcke, 2006). In our study, the fields are exchanged by the main processor after gathering all partitions over the whole model domain. To compile each model component linked to the PRISM library one has to set the link of the library in its makefile.

The next step is to choose the coupling parameters such as source and target grids, coupling frequency, field interpolation, etc. that are described in the file namcouple of
GMDD

5, 3261-3310, 2012

COSTRICE - three model online

coupling using

OASIS

H. T. M. Ho et al.

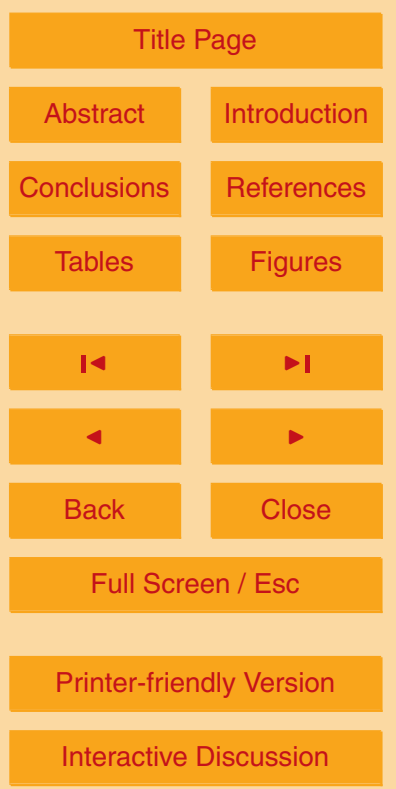


OASIS3. Examples of the file namcouple are shown in Tables $\mathrm{C} 1$ and $\mathrm{C} 2$ as well as by Valcke (2006).

The interpolation method used in this study is the N-nearest-neighbour distance weighted interpolation (DISTWGT) which is necessary for the local multiple rotated 5 coordinates of TRIMNP. Some errors are caused by the interpolation, hence the less interpolation is used the less difference between the source grid and the target grid occurs. Thus, for example, the total radiation energy flux or total precipitation are calculated in CCLM before being passed to TRIMNP or CICE even some or all of its components are transferred, too.

10 The temporal coupling process amongst the three component models controlled by OASIS3 is displayed in Fig. 5 in which the running time step of CCLM (dta) is $300 \mathrm{~s}$, those of CICE (dti) and TRIMNP (dto) are $240 \mathrm{~s}$, and the coupling time step of CCLM to TRIMNP is $1 \mathrm{~h}$ while other coupling time steps are $3 \mathrm{~h}$. At every running time step, each model sends the required exchange variables to OASIS3. However, only at the 15 coupling time, the sent data arrives at the receiving model. If LAG is set to 0 , data is derived exactly at the coupling time step. But in this case, in order to avoid a deadlock situation, the sequence index must be defined for each of the coupled fields corresponding to the given order. For example, firstly, the state variables from CCLM are sent to TRIMNP (SEQ = 1), then the SST, salinity, etc. of TRIMNP are passed to CICE $(S E Q=2)$ and then sea ice skin and water temperature, etc. of CICE are passed to TRIMNP $(S E Q=3)$ and so on. Unfortunately, in our coupled system, the deadlock happens after running $3 \mathrm{~h}$ because at the same time all three models send and need data and that results in a loop of waiting. To solve this deadlock, the three models are set to run simultaneously (SEQ $=1$ for all exchanged fields) and LAG is set to the running time step (in seconds) of the component model which sends the data. Consequently, the exchange time is one running time step earlier than the coupling time step and no model has to wait in the loop as it already receives data of the previous step from the sending model to calculate for the current step. However, due to the LAG, at the first running step, OASIS reads data from the restart files and sends

\section{GMDD}

$5,3261-3310,2012$

COSTRICE - three model online

coupling using

OASIS

H. T. M. Ho et al.

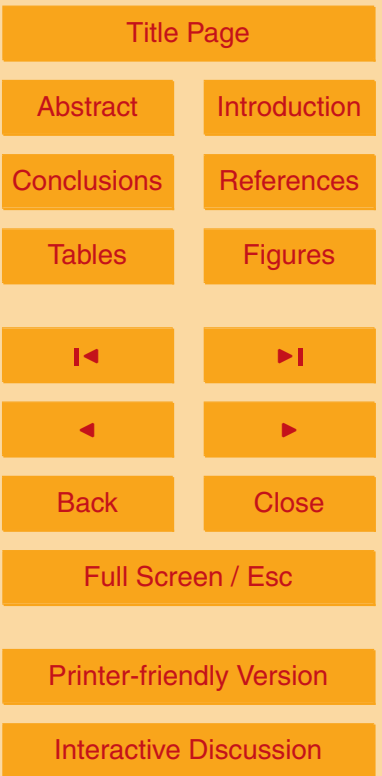


data to all three models. Data sent at the coupling time may be instantaneous, averaged or accumulated values since the last coupling time depending on the status of the variables. For example, rain and snow rates or heat fluxes are averaged for the period between the last and the current coupling time because they alter significantly 5 timestep-by-timestep, total precipitation is passed instantaneously as it is already accumulated hourly in CCLM, and wind components are passed instantaneously since alternative changes in wind direction may obscure wind speed values if wind components are averaged. At the end of each month, data is written in the restart file to initiate the coupling for the next month.

10 At the very beginning of the coupling process (1 January 1997 in this case study), the atmospheric forcings are passed from CCLM to TRIMNP and CICE but the SST of TRIMNP is initialized from uncoupled TRIMNP simulation. Therefore, the SST is too cold because of the direct influence of the cold air temperature above (due to the lack of sea ice scheme in TRIMNP), hence the sea ice concentration that is formed based on the surface temperature of TRIMNP is overestimated over Bothnian Bay. Additionally, the skin temperature in CICE is set to $-1.8^{\circ} \mathrm{C}$ everywhere over sea ice. These unrealistic phenomena should not be accounted for to avoid a wrong feedback to the atmosphere model. That's why the first simulation month (January 1997) is considered as spin-up time before the two-way coupling starts. From the second month onward, CCLM receives SST from TRIMNP. In principle, the spin-up time should be set up longer as the ocean model is initialized with climatological data. Note that global models even need longer spin-up times. For a regional ocean model, Berni et al. (2008) set $5 \mathrm{yr}$ for the spin-up time. For the longer runs, we will analyse the spin-up behavior more in detail and choose the spin-up time accordingly.

25 Instead of SST only (as in TRIMNP without sea ice), the feedback mechanism from ocean and sea ice to atmosphere is transferred by the combination of the sea water temperature $T_{\text {Oce }}$ from TRIMNP and sea ice skin temperature $T_{\text {Ice }}$ from CICE weighted by the sea ice area $A_{\text {lce }}$. The basic equation used here is the Stefan-Boltzmann Law

$\mathrm{HFL}=\varepsilon \sigma \mathrm{TS}^{4}$
GMDD

$5,3261-3310,2012$

COSTRICE - three model online

coupling using

OASIS

H. T. M. Ho et al.

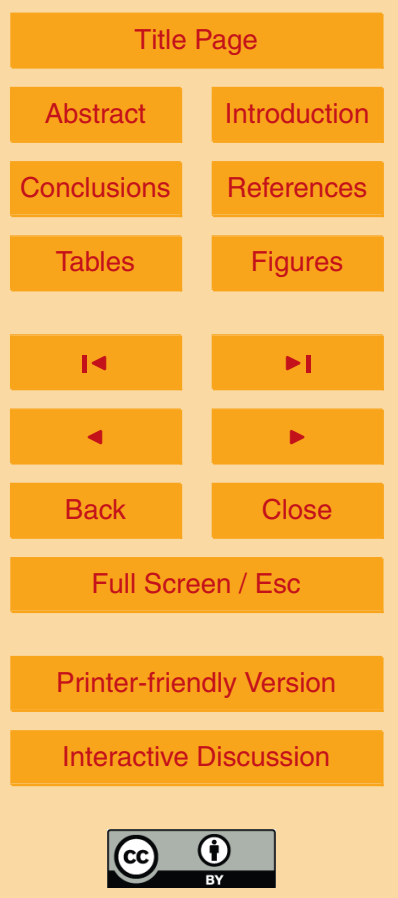


where TS is the skin temperature sent to CCLM at a grid point; HFL is the heat flux from surface to atmosphere in the grid box. TS can be formulated from Eq. (1):

GMDD

$\mathrm{TS}=\sqrt[4]{\frac{\mathrm{HFL}}{\varepsilon \sigma}}$

As in winter, both ice and sea water exist in the grid box, the heat flux is calculated as:

$5 \mathrm{HFL}=\varepsilon \sigma T_{\text {Ice }}^{4} \times A_{\text {Ice }}+\varepsilon \sigma T_{\text {Oce }}^{4} \times\left(1-A_{\text {Ice }}\right)$

where $T_{\text {Ice }}$ is the sea ice skin temperature, $A_{\text {Ice }}$ is the sea ice area, $T_{\text {Oce }}$ is the sea water temperature.

\subsection{How to define the suitable coupling time}

As mentioned in Sect. 1, coupling times of $6 \mathrm{~h}$ or a day chosen in many studies are likely 10 too long. Moreover, the Baltic Sea is a shallow sea with a very inhomogeneous distribution of land and water surfaces leading to rapid variations of SST are rapid on small spatial and temporal scales which are important for the interaction with the atmosphere (Gustafsson et al., 1998). Thus, $6 \mathrm{~h}$ or longer seems to be too long to adequately represent interactions between ocean and atmosphere over this region. Especially, as the 15 atmospheric response to SST is rapidly redistributed vertically (Neelin et al., 1994), the exchange time from atmosphere to other components should be shorter. For instance, kilometer-scale free convections with a life time of minutes to hours will be created if the surface is substantially warmer than the overlying air as mixing spontaneously occurs in order to redistribute the heat (Rafferty, 2011).

20 In order to determine how often the coupling process should be taken into account, we consider how fast and how significant atmosphere and sea surface temperature change during time periods of one to several hours. In this respect, we analyse model data instead of observations to find the optimal coupling time step for two reasons. First, appropriate observations with a high temporal resolution and suitable locations

COSTRICE - three model online coupling using OASIS

H. T. M. Ho et al.

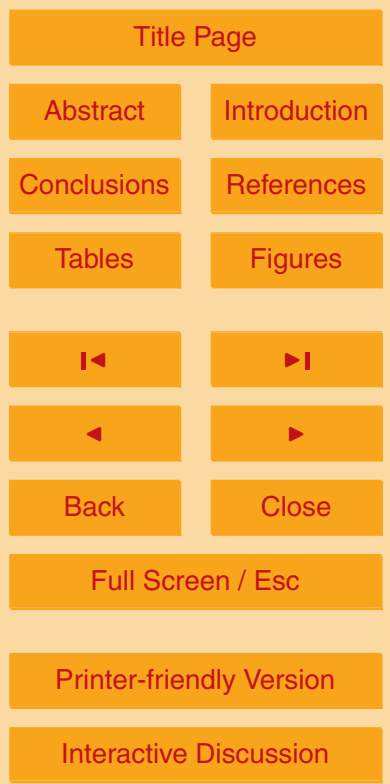

Interactive Discussion 
are hardly available. Second, the coupling time step should be adequate within the chosen coupled model system and the respective model component grid resolution. Therefore, following is the investigation for long term simulations of the uncoupled version of CCLM and TRIMNP.

5 Firstly, we calculated the 1-, 3- and 6-h changes (denoted by d1, d3, d6) of wind components at $10 \mathrm{~m}$ height (denoted by U10M and V10M) over Bothnian Bay (BB), Bothnian Sea (BS), central Baltic Proper (BP), Arkona Sea (Ark), Skagerrak Strait (Ska) and Gulf of Finland (GF) from the $63 \mathrm{yr}$ simulation of the uncoupled version of CCLM from 1948 to 2010 (with resolution of $0.22 \times 0.22^{\circ}$ and 40 vertical levels). The 10 hourly data is selected at one grid box in the centre of each sub-region. The U10M and $\mathrm{V} 10 \mathrm{M}$ averages are determined using their absolute values considering that the alternative changes in wind direction do not obscure the mean value. The changes are transformed to percent values by dividing the changes with the annual mean wind velocity. Then the changes in percent are used to calculate the frequency at which these 15 changes occur (denoted by FC) over categories ranging from $-100 \%$ to $100 \%$. The results for Ark, BB and BP (Fig. 6) show that FC has different magnitudes, especially in the case of $\mathrm{d} 1$, but common distributions over the sub-regions. The FC distributions of U10M (Fig. 6a) and V10M (Fig. 6b) are also similar. In both cases, the d1 distribution centers around changes up to $\pm 5 \%$ with a FC of $32-42 \%$ while the changes larger than $\pm 10 \%$ of the wind velocity occur with a FC of $35-40 \%$, and the changes larger than $\pm 20 \%$ have $\mathrm{FC}$ of $8-14 \%$. FC distributions are similar in summer and winter although the FCs larger than $\pm 10 \%$ and $\pm 20 \%$ are slightly higher in summer than in winter (not shown).

The probability of larger wind velocity changes is higher in the cases of $d 3$ and $d 6$ than in d1. For example, in Fig. 6a, the FC of more than $20 \%$ of U10M over Baltic Proper (BP) is around $12 \%$ for $\mathrm{d} 1$ but may reach $46 \%$ and $64 \%$ for $\mathrm{d} 3$ and $\mathrm{d} 6$, respectively. In COSTRICE, during the time between two coupling time steps $k$ and $k+1$, value of the exchanged field is kept as at the $k$ step. Therefore, if CCLM provides wind information every 3 or $6 \mathrm{~h}$, the hourly changes are missed and probably subsequent
GMDD

$5,3261-3310,2012$

COSTRICE - three model online

coupling using

OASIS

H. T. M. Ho et al.

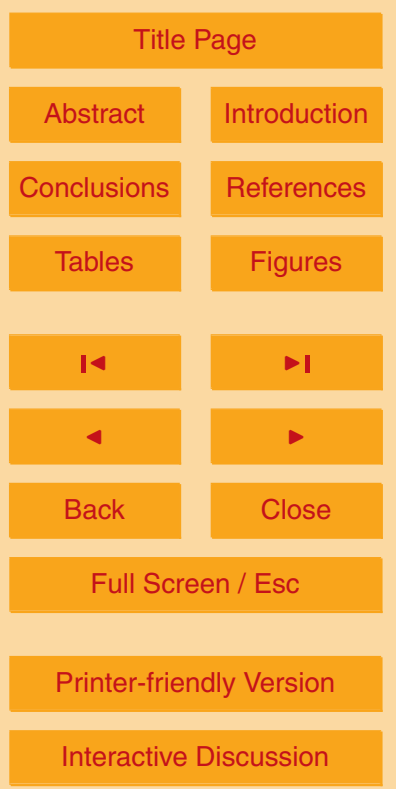


sudden jumps of wind forcing at the coupling times may lead to wrong wind-driven currents in the ocean model. Hence, 1-h data exchange is chosen to connect CCLM with TRIMNP. As the sea ice surface is more dense and solid than water, its thermal conductivity is less sensitive to changes in the atmospheric forcing. Therefore, a coupling 5 time step of $3 \mathrm{~h}$ is sufficient to pass CCLM's output to CICE.

As water has a greater density than air, it is also more thermally conductive than air, so that considerable changes of SST may occur in time periods of one to several hours. Moreover, SST behaves differently in warm and cold seasons due to diurnal heating and sea ice formation/melting, respectively. Hence, the 1-, 3-, 6-, 12- and 24-h 10 changes (denoted by d1, d3, d6, d12, d24) of SST (K) are calculated for warm (May to September) and cold (remaining part of the year) seasons using a $28 \mathrm{yr}$ simulation of TRIMNP from 1980 to 2007. Using the time-series of SST changes, exceedance frequencies of these changes (denoted by EFC) are determined over SST-change bins of $0.5 \mathrm{~K}$. The EFC of a given value is the frequency with which the data exceeds the

value. In general, in the warm season, the EFC distribution over the 6 areas is similar. In the cold season, BB and GF have the same distribution while BP, BS, Ark and Ska share another distribution. This is likely associated with the existence of more sea ice over BB and GF in winter time that is quite rare in the other four areas. Sea ice causes more frequent changes of sea water temperature when it expands and retreats or freezes and melts. Due to the similarity of the EFC distribution, Fig. 7 shows only the result for $\mathrm{BB}$ and $\mathrm{BP}$ in warm and cold seasons. In both seasons, the 1-h change d1 is mostly less than $0.5 \mathrm{~K}$. In the warm season, for d3, the EFC of $0.5 \mathrm{~K}$ is $30-40 \%$ and that of $1.0 \mathrm{~K}$ is $6 \%$. For $\mathrm{d} 6$, however, $23 \%$ and $33 \%$ of the sample have SST changes of more than $1 \mathrm{~K}$ over BB and BP, respectively. Only $5 \%$ of the sample of $\mathrm{d} 6$ has changes larger than $2 \mathrm{~K}$. The $\mathrm{d} 12$ changes are much higher than for $\mathrm{d} 6$ due to the night-day contrast. For example, $40-50 \%$ of the d12 sample has changes larger than $1 \mathrm{~K}$ and $20-25 \%$ has changes larger than $2 \mathrm{~K}$. The daily d24 change is weaker than for d12 but still larger than for d6. For instance, over BB, the EFC of $1.5 \mathrm{~K}$ in the case of $\mathrm{d} 6$, d12 and d24 are $14 \%, 30 \%$ and $20 \%$, respectively. In the cold season, on the contrary,
GMDD

$5,3261-3310,2012$

COSTRICE - three model online

coupling using

OASIS

H. T. M. Ho et al.

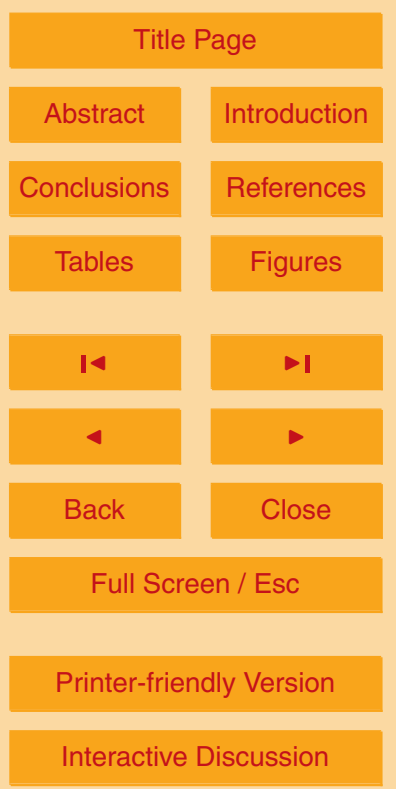


d24 is greater than d12 over BB and GF, but they are similar over other sub-regions. Even though, the SST changes are negligible in winter time over all sub-regions and time periods. For example, the EFC of $1.0 \mathrm{~K}$ is only $10-15 \%$ in the cases of $\mathrm{d} 12$ and d24 over BB.

5 Therefore, we conclude that a 3-h interval is recommended to pass SST from TRIMNP to CCLM and CICE. During $3 \mathrm{~h}$, most of the changes are smaller than $1 \mathrm{~K}$. Larger changes do not occur very often so that sudden jumps of SST are limited at the coupling time step. These jumps will occur more often with longer coupling time periods, such as 6, 12 or even $24 \mathrm{~h}$. Nevertheless, as the changes of SST are small in the 10 cold season, an experiment is planned to test alternative coupling times of 3 and $6 \mathrm{~h}$ for warm and cold seasons, respectively, while passing SST from TRIMNP to CCLM and CICE. This strategy helps to save computing time.

\subsection{Exchange state variables or fluxes?}

Another question arising when one is working with a coupled system is whether the 15 state variables or fluxes should be transferred amongst component models, especially in the case of sensible and latent heat fluxes. Rummukainen et al. (2001) utilized a vertically resolved, box-like ocean model (Omstedt and Nyberg, 1996) coupled to a regional atmosphere model via state variables. In contrast, Döscher et al. (2002) calculated the fluxes within the atmosphere on an atmospheric grid $(44 \mathrm{~km})$, which is coarser 20 than the ocean grid $(11.1 \mathrm{~km})$ to neglect the sub-atmosphere-grid scale variability of the sea surface, and passed them to the ocean model which only calculated the longwave upward radiation by itself. This is also the method applied in our coupled system.

In CCLM, surface fluxes of momentum, heat and water vapour are computed by a surface layer scheme (based on turbulent kinetic energy) including a laminar25 turbulent roughness layer and the option for a stability-dependent drag law formulation of momentum, heat and moisture fluxes according to the similarity theory of Louis (Schaettler, 2011). In TRIMNP, heat fluxes are calculated based on the bulk formula of Isemer and Hasse (1985) using the difference between water and near surface air

GMDD

$5,3261-3310,2012$

COSTRICE - three model online

coupling using

OASIS

H. T. M. Ho et al.

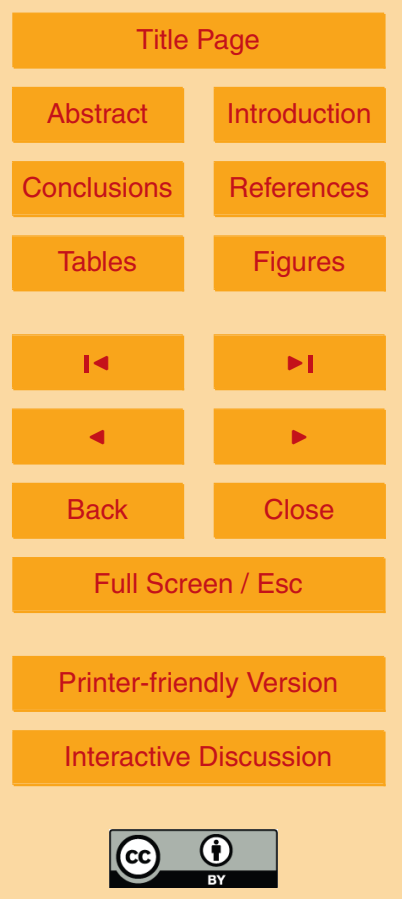


temperature and humidity. In order to avoid a conflict at the interface induced by the difference of heat flux calculations and resolutions, heat fluxes from CCLM should be transferred to TRIMNP instead of being computed by TRIMNP itself. Neelin et al. (1994) showed that although heat fluxes are calculated using the atmospheric boundary-layer 5 parameterizations based on SST from the previous interval, the important dependence of heat flux on SST is retained as long as the heat flux coupling interval is sufficiently small. Based on this study, we would indicate one more reason to choose the coupling time of $1 \mathrm{~h}$ from CCLM to TRIMNP.

To demonstrate the difference between the two methods, we conducted two experi10 ments STERva and STERhf (see Table 2). In the case of STERva, TRIMNP calculates the sensible and latent heat fluxes based on the wind speed and the air-sea differences of temperature and humidity derived from CCLM. In the STERhf case, the heat fluxes are directly passed from CCLM to TRIMNP. Plotted in Figs. 8 and 9 are the monthly averaged sensible and latent heat fluxes, respectively, in May 1997, where the down15 ward flux has a positive value. Obviously, in this case, both experiments overestimate the absolute values of sensible and latent heat fluxes (Figs. 8 and 9, respectively) compared to ERA-interim data. But in general, the fluxes simulated by STERhf (Figs. 8b and $9 b$ ) are closer to the ERA-interim data than by STERva (Figs. $8 a$ and 9a). The strong negative latent heat flux of STERva means the ocean loses very much heat to the atmosphere (Fig. 9a). This heat loss may not be compensated by the positive sensible heat flux (Fig. 8a) thereby leading to a too cold SST simulated in STERva than in STERhf compared with OISST (see Figs. 10a, b and d).

Briefly, in our study, the better results are produced when the heat fluxes are passed from CCLM to TRIMNP. However, due to the coarse resolution of CCLM, the heat fluxes, especially the sensible heat flux (Fig. 8b) is affected by the land-sea mask along coastlines. That must be a reason why Döscher et al. (2002) planned to calculate the flux on the finest grid of the ocean model for all variables for the next development step of RCAO. As long as the ocean model has the capacity to simulate the fluxes better or as good as the atmosphere model, this is the more advantageous strategy. Due to the
GMDD

$5,3261-3310,2012$

COSTRICE - three model online

coupling using

OASIS

H. T. M. Ho et al.

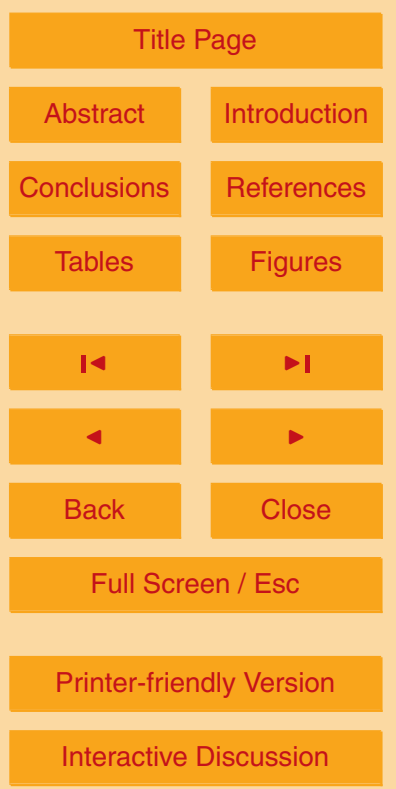


higher resolution, the ocean model does not only provide more detailed fluxes along the coastlines but also calculates and updates them more often (every running time step) than receiving them only at every coupling time (1 $\mathrm{h}$ or even longer). Meier and Döscher (2002) also supposed that as sea ice and SST in the Baltic Sea are sensitive 5 to biases of simulated surface heat fluxes, the calculation of the energy cycle should be included in ocean models. Nevertheless, as the simulation of heat fluxes in TRIMNP is inferior to that of CCLM as mentioned above, our coupled system in the coupled experiment CPERAi (see Table 2) also applies the method of flux exchanging as used in STERhf and will be improved regarding to the coarse resolution effect on the fluxes 10 near the coastlines in the future (e.g. by setting up CCLM in a similar resolution as TRIMNP). Similar to STERhf, the simulated heat fluxes in CPERAi are close to the ERA-interim data (not shown). However, due to the interactions and feedbacks, SST of CPERAi is improved to be closer to OISST than that of STERhf. As an example, Fig. 10 presents the monthly mean SST in May 1997 (see Figs. 10b, c and d).

In winter, CPERAi improves the SST over the ice-free areas compared to the uncoupled run STERhf (Fig. 11). In the uncoupled run (Fig. 11a), TRIMNP mostly underestimates the OISST, except over the Bothnian Bay where sea ice exists (see Fig. 12c). The reason is TRIMNP doesn't take the sea ice into account so SST over the sea ice is as cold as the air above, and to avoid this unrealistic water temperature, TRIMNP sets SST to $-1{ }^{\circ} \mathrm{C}$ if the sea water is colder than the freezing temperature threshold. The simulated SST of the coupled run CPERAi (Fig. 11b) is closer to the OISST but still is underestimated over Kattegat and Atlantic Ocean and slightly overestimated over the Bothnian Bay and Baltic Proper. In order to overcome the bias in TRIMNP due to lack of a sea ice scheme, CICE is used to determine the sea ice skin temperature 25 (Tsfc). CICE simulates the ice concentration well compared to the NOAA data although there's an underestimation over the Bothnian Bay (not shown). In areas of mixed sea ice and open water, the Tsfc from CICE is combined with the SST from TRIMNP using Eqs. (3) and (2), which leads to skin temperature comparable to the ERA-interim data (Fig. 12a, b). Now over the ice-free areas, the skin temperature of CPERAi is closer to
GMDD

$5,3261-3310,2012$

COSTRICE - three model online coupling using OASIS

H. T. M. Ho et al.

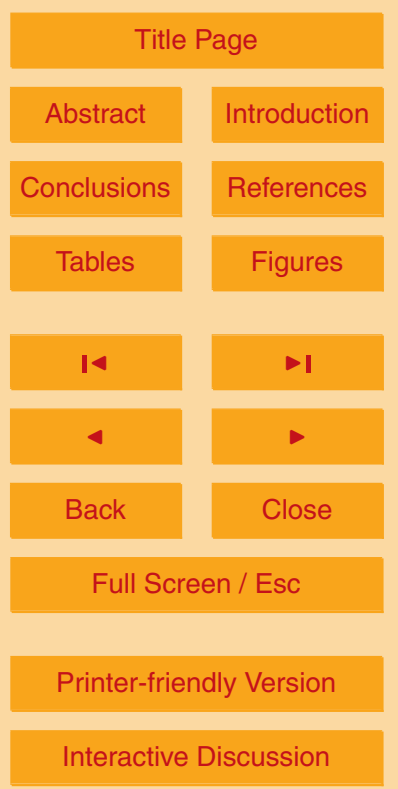


the OISST and over the sea ice area the skin temperature is close to the ERA-interim data. The improvement of CPERAi surface temperatures can probably be attributed to the interactions and feedbacks of atmosphere, ocean and sea ice represented in the coupled system.

5 As an example for the skill of the coupled system, Fig. 13 presents the daily area averaged SST of NOAA OISST data and of TRIMNP in the uncoupled run STERhf (using ERA-interim data) and in the coupled run CPERAi from 1 February to $31 \mathrm{De}-$ cember 1997 over 5 of 9 sub-regions (R1 to R9 in the panel f of Fig. 13) as defined by Tedesco et al. (2009). In analysis of simulation results, January is disregarded because 10 of spin-up of the coupled system (see Sect. 3.1). The simulated SST for sub-region R2 is similar to that of R1 (Fig. 13a), R3 is similar to R4 (Fig. 13b), R7 is similar to R6 (Fig. 13d) and R9 is similar to R8 (Fig. 13e). In this example, the uncoupled version of TRIMNP tends to overestimate OISST in the summer months May-July and underestimate in the remaining months of the year. From February to April, the cold bias of 15 STERhf over Baltic Proper and Bothnian Bay and Sea (R3, R4, R8, R9) is smaller than over North Sea (R1), Kattegatt (R2), Gulf of Riga (R6) and Gulf of Finland (R7). From August to December, the cold bias of 2 degrees occurs over all of sub-regions except $\mathrm{R} 8$ and R9. The simulation uncertainties of uncoupled version may be caused by the too short spin-up time for ocean model in this case study (mentioned in Sect. 3.1). 20 The SST of CPERAi is much closer to the OISST than the STERhf. However, a robust conclusion may be made after a long-term run of CPERAi is assessed in the future.

\section{Conclusions and outlook}

This paper introduces the two-way online coupled system COSTRICE which comprises three model components, the atmospheric RCM CCLM, the ocean model TRIMNP and the sea ice model CICE. COSTRICE is set up to run in parallel on the super computing system IBM-power 6 of DKRZ. Central issues are the coupling technique and the basis for choosing the coupling time step and exchanged fields. Using the coupler OASIS3,
GMDD

$5,3261-3310,2012$

COSTRICE - three model online coupling using OASIS

H. T. M. Ho et al.

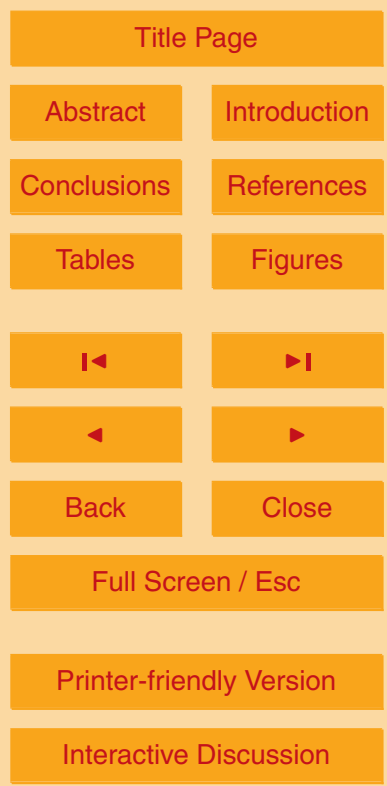


changes to the original source code of the component models were small and mainly limited to a few additional calls regarding the library of OASIS3 (Sect. 3.1). The coupling time step was objectively defined (Sect. 3.2) using long term simulations of the uncoupled versions of CCLM (1948-2010) and TRIMNP (1980-2007). The basis for 5 transferring fluxes instead of only state variables amongst the three component models was inferred (Sect. 3.3) from the results of several model experiments that were compared to the ERA-interim data. Based on those investigations, the coupled system was set up to run an experiment (CPERAi) for the year 1997 where the first month (January) was regarded as "spin-up time" before two-way coupling. In general, CPERAi improves 10 the SST over the ice-free area compared to the standalone version of TRIMNP due to the interactions and feedbacks of atmosphere, ocean and sea ice represented in the coupled system. However, as only one year simulation was considered, a more robust conclusion may be made after results from long-term run of CPERAi is available in the near future.

15 Besides, some more sensitivity tests need to be conducted to answer the question how long the whole coupled system needs as spin-up time to go harmoniously together. In our study, the feedback of the ocean to the atmosphere is taken into account via SST. However, the exchange of momentum between the atmosphere and the ocean plays a critical role in determining climate (e.g. Gill, 1982). The wind-dependent roughness of the surface directly influences the air-sea fluxes of all other quantities (e.g. sensible and latent heat, water, and gases) (Rothrock et al., 1999). Hence, in the next step the momentum exchange should be included in the system.

Another component currently missing is a hydrological discharge (HD) model. In this study, TRIMNP is using measured freshwater inflows but for climate projections in future studies a HD model is required to provide freshwater information to TRIMNP. As reported in HELCOM (2007), the external water budget of the Baltic Sea is dominated by water import from riverine discharge, inflowing North Sea water, and net precipitation (precipitation minus evaporation) and export by Baltic Sea water outflow into the North Sea. Moreover, regionally, the nordic part of the Baltic drainage basin has shown
GMDD

$5,3261-3310,2012$

COSTRICE - three model online

coupling using

OASIS

H. T. M. Ho et al.

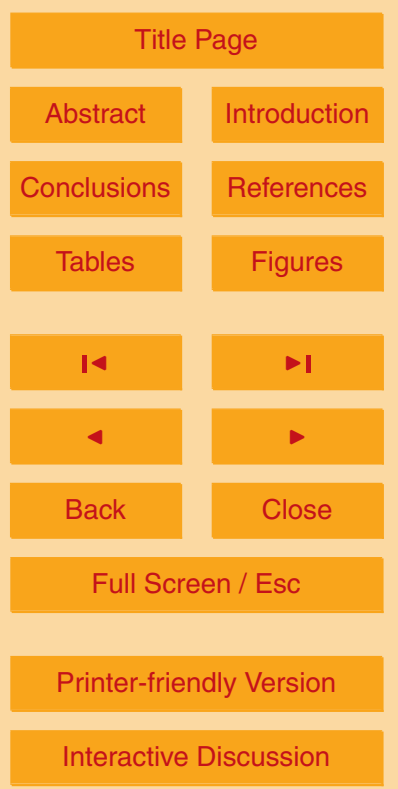


an increasing trend in runoff during winter (December-February) and spring (MarchMay) during 1921-2004 so that changing runoff conditions should be considered in climate simulations, especially as the large amount of freshwater inflow into the Baltic Sea controls the low salinity of the Baltic Sea surface water that strongly effects the 5 freezing potential capacity of water over this region. Therefore, it is strongly recommended that a HD model is included in the coupled system COSTRICE in the future.

Acknowledgement. This study has been funded by the project REKLIM. The authors wish to show a gratitude to CERFACS (France), especially S. Valcke, for the valuable support of the coupling technique, to the German Climate Computing Center (DKRZ) for the high computing 10 performance as well as for providing the CERA data, to the IRI/LDEO Climate Data Library (http://iridl.Ideo.columbia.edu) for providing the LEVITUS94 Ocean Climatology data and the NOAA high resolution data, to Laurent Roblou from LEGOS in Toulouse, France, for providing the software FES2004 for generating initial and boundary values for water level, to the ECMWF for providing ERA-Interim data, to the Los Alamos National Laboratory (US), espe15 cially E. C. Hunke, for the sea ice model source code and useful discussions. The authors wish to thank the anonymous reviewers for their very useful suggestions and comments.

\section{References}

Artale, V., Calmanti, S., Carillo, A., Dell'Aquila, A., Hermann, M., Pisacane, G., Ruti, P. M., Sannino, G., Striglia, M. V., Giorgi, F., Bi, X., Pal, J. S., and Rauscher, S.: An atmosphereocean regional climate model for the mediterranean area: assessment of a present climate simulation, Clim. Dynam., 35, 721-740, 2009.

Bennartz, R., Lorenz, P., and Jacob, D.: Validation of the regional coupled climate model BALTIMOS using passive microwave satellite data (AMSR-E), Theor. Appl. Climatol., doi:10.1007/s00704-009-0178-x, 2009.

25 Bernie, D. J., Guilyardi, E., Madec, G., Slingo, J. M., Woolnough, S. J., and Cole, J.: Impact of resolving the diurnal cycle in an ocean-atmosphere GCM, Part 2: A diurnally coupled CGCM, Clim. Dynam., 31, 909-925, 2008.

Casulli, V. and Cattani, E.: Stability, accuracy and efficiency of a semi-implicit method for three dimensional shallow water flow, Comput. Math. Applic., 27, 99-112, 1994.

3285
GMDD

$5,3261-3310,2012$

COSTRICE - three model online

coupling using

OASIS

H. T. M. Ho et al.

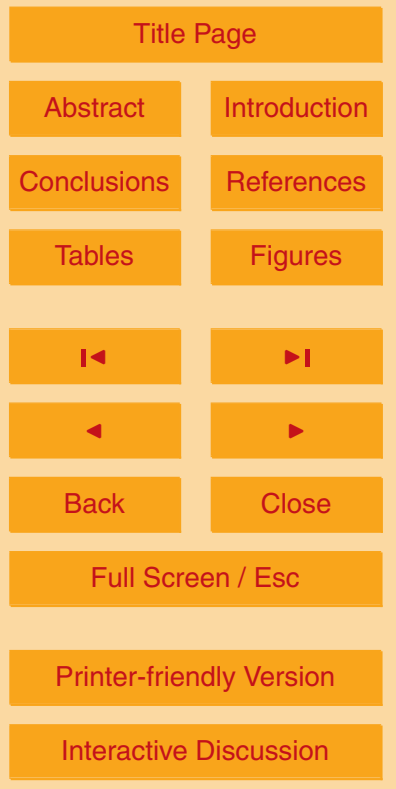

Interactive Discussion 
Dai, A.: Precipitation characteristics in eighteen coupled climate models, J. Climate, 19, 46054630, 2006.

Danabasoglu, G., Large, W. G., Tribbia, J. J., Gent, P. R., Briegleb, B. P., and McWilliams, J. C.: Diurnal coupling in the tropical oceans of CCSM3, J. Climate, 19, 2347-2365, 2006.

5 Davies, H. C.: On the lateral boundary conditions for the primitive equations, J. Atmos. Sci., 30, 147-150, 1973.

Davies, H. C.: A lateral boundary formulation for multi-level prediction models, Q. J. Roy. Meteor. Soc., 102, 405-418, 1976.

Davies, H. C. and Turner, R. E.: Updating prediction models by dynamical relaxation: an examination of the technique, Q. J. Roy. Meteor. Soc., 103, 225-245, 1977.

Davin, E. L., Stoeckli, R., Jaeger, E. B., Levis, S., and Seneviratne, S. I.: COSMO-CLM2: a new version of the COSMO-CLM model coupled to the community land model, Clim. Dynam., 37, 1889-1907, doi:10.1007/s00382-011-1019-z, 2011.

Delnore, V. E.: Diurnal variation of temperature and energy budget for the oceanic 15 mixed layer during BOMEX, J. Phys. Oceanogr., 2, 239-247, doi:10.1175/15200485(1972)002<0239:DVOTAE>2.0.CO;2, 1972.

Döscher, R., Willen, U., Jones, C., Rutgersson, A., Meier, H. E. M., and Hansson, U.: The development of the coupled oceanatmosphere model RCAO, Boreal Env. Res., 7, 183-192, 2002.

Dorn, W., Dethloff, K., Rinke, A., Frickenhaus, S., Gerdes, R., Karcher, M., and Kauker, F.: Sensitivities and uncertainties in a coupled regional atmosphere-ocean-ice model with respect to the simulation of Arctic sea ice, J. Geophys. Res., 112, D10118, doi:10.1029/2006JD007814, 2007.

Elizalde, A. and Jacob, D.: Water vapor transport and precipitation over the Mediterranean region as simulated by a regional atmosphere-ocean coupled model, Clim. Dynam., submitted, 2012.

Elizalde, A., Sein, D., Mikolajewick, U., and Jacob, D.: Technical Report: Atmosphere-oceanhydrology coupled regional climate model, Max Planck Institute for Meteorology, Germany, http://www.remo-rcm.de/fileadmin/user_upload/remo/UBA/pdf/TechnicalReport.pdf, 2010.

30 Gentemann, C. L. and Minnett, P. J.: Radiometric measurements of ocean surface thermal variability, J. Geophys. Res., 113, C08017, doi:10.1029/2007JC004540, 2008.
GMDD

$5,3261-3310,2012$

COSTRICE - three model online

coupling using

OASIS

H. T. M. Ho et al.

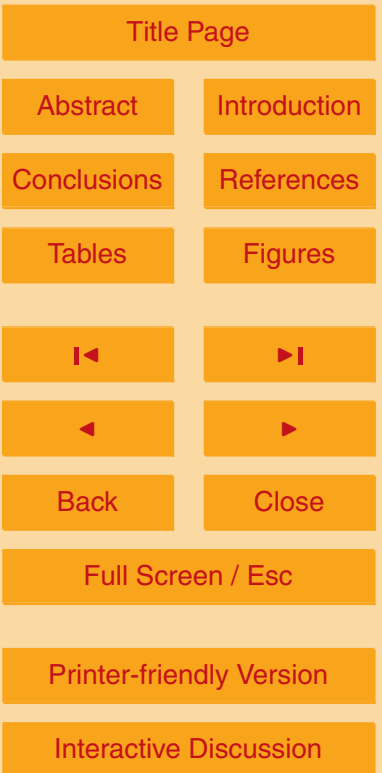


Gentemann, C. L., Minnett, P. J., and Ward, B.: Profiles of ocean surface heating (POSH): a new model of upper ocean diurnal warming, J. Geophys. Res., 114, C07017, doi:10.1029/2008JC004825, 2009.

Gill, A. E.: Atmosphere-Ocean Dynamics, Academic Press, Inc., San Diego, 662 pp., 1982.

5 Gustafsson, N., Nyberg, L., and Omstedt, A.: Coupling high-resolution atmosphere and ocean models for the Baltic Sea, Mon. Weather Rev., 126, 2822-2846, 1998.

Hagedorn, R., Lehmann, A., and Jacob, D.: A coupled high-resolution atmosphere-ocean model for the Baltic region, Meteorol. Z., 9, 7-20, 2000.

Halpern, D. and Reed, R.: Heat budget of the upper ocean under light winds, J. Phys. Oceanogr., 6, 972-976, doi:10.1175/1520-0485(1976)006<0972:HBOTUO>2.0.CO;2, 1976.

Ham, Y.-G., Kug, J.-S., Kang, I.-S., Jin, F.-F., and Timmermann, A.: Impact of diurnal atmosphere-ocean coupling on tropical climate simulations using a coupled GCM, Clim. Dynam., 34, 905-917, 2010.

HELCOM: Climate change in the Baltic Sea area - HELCOM thematic assessment in 2007, Baltic Sea Environmental Proceedings No. 111, 2007.

Hunke, E. C. and Lipscomb, W. H.: CICE: The Los Alamos Sea Ice Model. Documentation and Software User's Manual. Version 4.0, T-3 Fluid Dynamics Group, Los Alamos National Laboratory, Tech. Rep., LA-CC-06-012, 2008.

20 Isemer, H.-J. and Hasse, L.: The Bunker Climate Atlas of the North Atlantic Ocean, Vol. 2, Air-Sea Interactions, Springer-Verlag, 252 pp., 1985.

Jacob, D., Andrae, U., Elgered, G., Fortelius, C., Graham, L. P., Jackson, S. D., Karstens, U., Koepken, Chr., Lindau, R., Podzun, R., Rockel, B., Rubel, F., Sass, H. B., Smith, R. N. D., Van den Hurk, B. J. J. M., and Yang, X.: A comprehensive model intercomparison study investigating the water budget during the BALTEX-PIDCAP period, Meteorol. Atmos. Phys., 77, 19-43, 2001.

Jevrejeva, S., Drabkin, V. V., Kostjukov, J., Lebedev, A. A., Leppäranta, M., Mironov, Ye. U., Schmelzer, N., and Sztobryn, M.: Baltic Sea ice seasons in the twentieth century, Clim. Res., 25, 217-227, 2004.

30 Kapitza, H.: MOPS - a morphodynamical prediction system on cluster computers, in: High Performance Computing for Computational Science, VECPAR 2008. Vol. 5336 Toulouse (F), doi:10.1007/978-3-540-92859-1, 63-68, 2008.

GMDD

$5,3261-3310,2012$

COSTRICE - three model online coupling using OASIS

H. T. M. Ho et al.

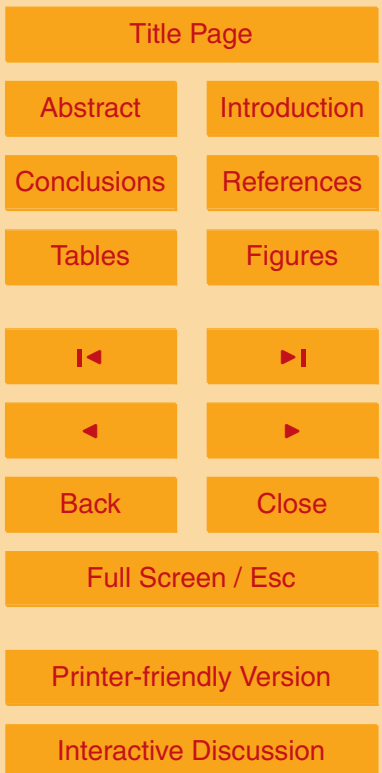

Interactive Discussion 
Kapitza, H. and Eppel, D.: Simulating morphodynamical processes on a parallel system, in: 6th International Conference on Estuarine and Coastal Modeling, Reston, VA (USA), 11821191, 2000.

Kirtman, B. and Vecchi, G. A.: Why Climate Modelers Should Worry About Atmospheric and 5 Oceanic Weather. The Global Monsoon System: Research and Forecast, 2nd Edn., edited by: Chang, C.-P., Ding, Y., Lau, N.-C., Johnson, R. H., Wang, B., and Yasunari, T., World Scientific Series on Asia-Pacific Weather and Climate, vol. 5, World Scientific Publication Company, 608 pp., 511-524, 2011.

Lefevre, F., Lyard, F. H., Le Provost, C., and Schrama, E. J. O.: FES99: a global tide finite element solution assimilating tide gauge and altimetric information, J. Atmos. Ocean. Technol., 19, 1345-1356, 2002.

Lehmann, A., Lorenz, P., and Jacob, D.: Modelling the exceptional Baltic Sea inflow events in 2002-2003, Geophys. Res. Lett., 31, 0094-8276, doi:10.1029/2004GL020830, 2004.

Lyard, F., Lefevre, F., Letellier, T., and Francis, O.: Modelling the global ocean tides: modern insights from FES2004, Ocean Dynamics, 56, 394-415, 2006.

Madec, G., Delecluse, P., Imbard, M., and Levy, C.: OPA version 8.1 ocean general circulation model reference manual, Technical Report, LODYC/IPSL, Note 11, Paris, France, 91 pp., 1998.

Manabe, S. and Bryan, K.: Climate calculations with a combined ocean-atmosphere model, J. $20 \quad$ Atmos. Sci., 26, 786-89, 1969.

Manabe, S., Bryan, K., and Spelman, M. J.: A global ocean-atmosphere climate model with seasonal variation for future studies of climate sensitivity, Dynam. Atmos. Oceans, 3, 393426, 1979.

McGuffie, K. and Henderson-Sellers, A.: A Climate Modelling Primer, 2nd Edn., John Wiley \& 25 Sons Ltd, Chichester, UK, 1997.

McGuffie, K. and Henderson-Sellers, A.: A Climate Modeling Primer, 3rd Edn., John Wiley \& Sons, New York, 280 pp., 2005.

Meier, H. E. M. and Döscher, R.: Simulated water and heat cycles of the Baltic Sea using a 3-D coupled atmosphere-ice-ocean model, Boreal Env. Res., 7, 327-334, 2002.

so Meier, H. E. M., Döscher, R., and Faxen, T.: A multiprocessor coupled ice-ocean model for the Baltic Sea: application to salt inflow, J. Geophys. Res., 108, 3273, doi:10.1029/2000JC000521, 2003.

GMDD

5, 3261-3310, 2012

COSTRICE - three

model online

coupling using

OASIS

H. T. M. Ho et al.

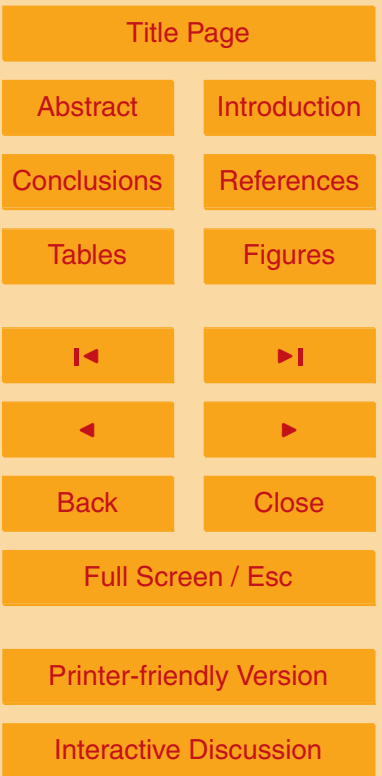

Interactive Discussion 
Meier, H. E. M., Döscher, R., and Halkka, A.: Simulated distributions of Baltic Sea-ice in warming climate and consequences for the winter habitat of the Baltic ringed seal, Ambio, 33, 249-256, 2004.

Minnett, P. J.: Variability of the sea-surface temperature: an overview, 2012 Ocean Sciences Meeting, 2012.

Neelin, J. D., Latif, M., and Jin, F.-F.: Dynamics of coupled ocean-atmosphere models: the tropical problem, Ann. Rev. Fluid Mech., 26, 617-659, 1994.

Omstedt, A. and Nyberg, L.: Response of Baltic Sea ice to seasonal, interannual forcing and to climate change, Tellus A, 48, 644-662, 1996.

10 Omstedt, A. and Rutgersson, A.: Closing the water and heat cycles of the Baltic Sea, Meteorol. Z., 9, 57-64, 2000.

Pohlmann, T.: Calculating the annual cycle of the vertical eddy viscosity in the North Sea with a three-dimensional baroclinic shelf sea circulation model, Cont. Shelf Res., 16, 147-161, 1996.

Pope, V. D., Pamment, J. A., Jackson, D. R., and Slingo, A.: The representation of water vapour and its dependence on vertical resolution in the Hadley Centre Climate Model, J. Clim., 14, 3065-3085, 2001.

Raible, C., Luksch, U., Fraedrich, K., and Voss, R.: North Atlantic decadal regimes in a coupled GCM simulation, Clim. Dynam., 18, 321-330, 2001.

20 Rafferty, J. P. (Ed.): Storms, Violent Winds, and Earth's Atmosphere, Britannica Educational Publishing in association with Rosen Educational Services, New York, 256 pp., 2011.

Rockel, B., Will, A., and Hense, A. (Eds.): Special issue: Regional climate modelling with COSMO-CLM (CCLM), Meteorol. Z., 17, 347-348, 2008.

Rodenhuis, G. S., Brink-Kjaer, O., and Bertelsen, J. A.: A North Sea model for Detailed Current and Water-Level Predictions, J. Petroleum Technol., 30, 1369-1376, 1978.

Rothrock, D. A., Abbott, M. R., Alley, R., Brewer, P. G., Brown, O., Busalacchi, A. J., Esaias, W. E., Esbensen, S. K., Freilich, M. H., Frew, J., Glover, D. M., Godfrey, J. S., Goyet, C., Holland, M. R., Matsunaga, T., Maynard, N. G., Muller-Karger, F., Niiler, P. P., Parslow, J., Peltzer, E. T., Schutz, B. E., Shum, C. K., Srokosz, M., Stewart, R., Strub, T., Walstad, L. J., Yoder, J. The State of Science in the EOS Program, NASA/Goddard Space Flight Center, Maryland, 115-162, 1999, available at: http://eospso.gsfc.nasa.gov/scienceplan/Ch3.pdf, 2012.

GMDD

5, 3261-3310, 2012

COSTRICE - three model online coupling using OASIS

H. T. M. Ho et al.

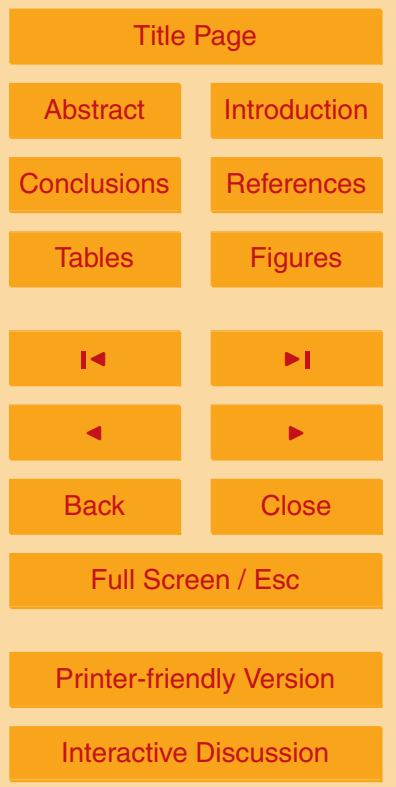


Rummukainen, M., Raeisaenen, J., Bringfelt, B., Ullerstig, A., Omstedt, A., Willen, U., Hansson, U., and Jones, C.: A regional climate model for Northern Europe: model description and results from the downscaling of two GCM control simulations, Clim. Dynam., 17, 339-359, 2001.

5 Rutgersson, A.: Water and Heat Exchange Processes over the Baltic Sea, Ph. D. Thesis in Meteorology, Uppsala University, Uppsala, 2000.

Rutgersson, A., Smedman, A.-S., and Omstedt, A.: Measured and simulated latent and sensible heat fluxes at two marine sites in the Baltic Sea, Bound.-Layer Meteorol., 99, 53-84, 2001.

10 Rutgersson, A., Omstedt, A., and Chen, Y.: Evaluation of the heat balance components over the Baltic Sea using four gridded meteorological data bases and direct observations, Nord. Hydrol., 36, 381-396, 2005.

Rutgersson, A., Carlsson, B., Smedman, A.: Modelling sensible and latent heat fluxes over sea during unstable, very close to neutral conditions, Bound.-Layer Meteorol., 123, 395-415, 2007.

Schaettler, U.: A Description of the Nonhydrostatic COSMO-Model Part V: Preprocessing, Consortium for Small-scale Modeling, available at: http://www.cosmo-model.org/content/model/ documentation/core/cosmolnt2lm.pdf, 2012.

Schrum, C.: Regionalization of climate change for the North Sea and the Baltic Sea, Clim. Res., 18, 31-37, 2001.

Schrum, C., Hübner, U., Jacob, D., and Podzun, R.: A coupled atmosphere/ice/ocean model for the North Sea and the Baltic Sea, Clim, Dynam., 21, 131-151, doi:10.1007/s00382-0030322-8, 2003.

Sheffield, J., Gopi, G., Wood, E. F.: Development of a 50-year high-resolution global dataset of meteorological forcings for land surface modeling, J. Climate, 19, 3088-3111, doi:10.1175/JCLI3790.1, 2006.

Soloviev, A. and Lukas, R. B.: Observations of large diurnal warming events in the near-surface layer of the western equatorial Pacific warm pool, Deep-Sea Res. Pt. I, 44, 1055-1076, doi:10.1016/S0967-0637(96)00124-0, 1997.

30 Sun, S. and Hansen J. E.: Climate simulations for 1951-2050 with a coupled atmosphere-ocean model, J. Climate, 16, 2807-2826, doi:10.1175/15200442(2003)016<2807:CSFWAC>2.0.CO;2, 2003.
GMDD

5, 3261-3310, 2012

COSTRICE - three model online

coupling using

OASIS

H. T. M. Ho et al.

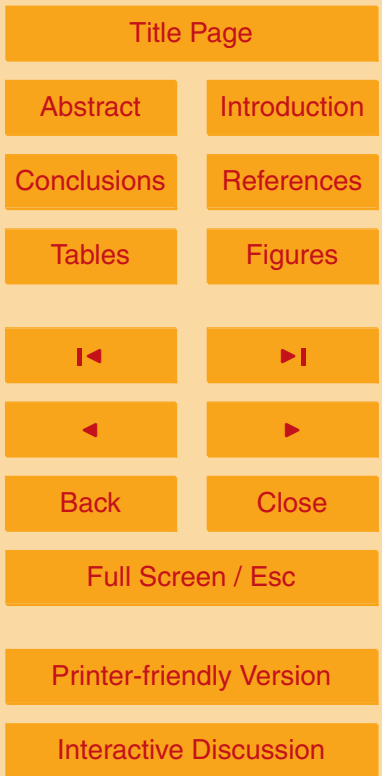


Taylor, K. E., Stouffer, R. J., and Meehl, G. A.: A summary of the CMIP5 experimental design, available at: http://cmip-pcmdi.Inl.gov/cmip5/docs/Taylor_CMIP5_design.pdf, 2012.

Taylor, K. E., Stouffer, R. J., and Meehl, G. A.: The CMIP5 Experiment Design, Bull. Amer. Meteorol. Soc., 93, 485-498, doi:10.1175/BAMS-D-11-00094.1, 2012.

5 Tedesco, L., Vichi, M., Haapala, J., and Stipa, T.: An enhanced sea-ice thermodynamic model applied to the Baltic Sea, Boreal Environ. Res., 14, 68-80, 2009.

Terray, P., Kakitha, K., Masson, S., Madec, G., Sahai, A. K., Luo, J.-J., and Yamagata, T.: The role of the frequency of SST coupling in the Indian Monsoon variability and monsoon-ENSO-IOD relationships in a global coupled model, Clim. Dynam., 39, 729-754, 10 doi:/10.1007/s10236-005-0024-3, 2012.

Tian, T., Boberg, F., Christensen, O. B., and Christensen, J. H.: The importance of choosing interactive coupling on the atmosphere in the Baltic Sea region and in the North Sea-Baltic Sea transition, Poster XY257, EGU2012-5361, 2012.

Valcke, S.: OASIS3 User Guide (oasis3_prism_2-5), PRISM Support Initiative Report No 3. 15 CERFACS, Toulouse, France, 64 pp., 2006.

von Storch, H., Langenberg, H., and Feser, F.: A spectral nudging technique for dynamical downscaling purposes, Mon. Weather Rev., 128, 3664-3673, 2000.

Washington, W. M., Semtner, A. J., Meehl, G. A., Knight, D. J., and Mayer, T. A.: A general circulation experiment with a coupled atmosphere, ocean, and sea ice model, J. Phys. Oceanogr., 20 10, 1887-1908, 1980.

Webster, P. J., Clayson, C. A., and Curry, J. A.: Clouds, radiation, and the diurnal cycle of sea surface temperature in the tropical western Pacific, J. Clim., 9, 1712-1730, doi:10.1175/1520-0442(1996)009<1712:CRATDC>2.0.CO;2, 1996.

Woth, K., Weisse, R., and von Storch, H.: Climate change and North Sea storm surge extremes: an ensemble study of storm surge extremes expected in a changed climate projected by four different regional climate models, Ocean Dynam., 56, 3-15, doi:10.1007/s10236-005-00243, 2006.

Zhang, Y.: An observational study of atmosphere-ocean interaction in the northern oceans on interannual and interdecadal time-scales, Ph.D. Dissertation, Univ. of Washington, Seattle, WA, 162 pp., 1996.

GMDD

$5,3261-3310,2012$

COSTRICE - three model online

coupling using

OASIS

H. T. M. Ho et al.

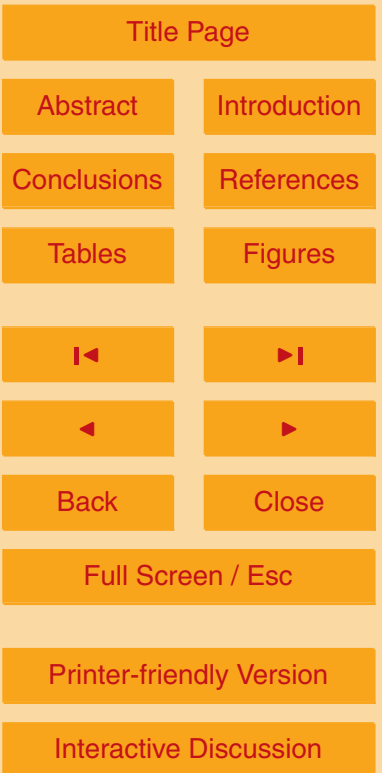




\section{GMDD}

$5,3261-3310,2012$

COSTRICE - three model online coupling using OASIS

Table 1. The configuration of the three component models.

\begin{tabular}{llll}
\hline & CCLM & TRIMNP & CICE \\
\hline Horizontal resolution & $0.44^{\circ} \times 0.44^{\circ}$ & $12.8 \mathrm{~km}$ & $12.8 \mathrm{~km}$ \\
Vertical resolution & 32 layers & 50 layers & 5 ice-categories \\
Domain (grid points) & $126 \times 123$ & $200 \times 230$ & $120 \times 120$ \\
Running time step & $300 \mathrm{~s}$ & $240 \mathrm{~s}$ & $240 \mathrm{~s}$ \\
Computing resource & $9 \times 9=81$ tasks & $7 \times 14=98$ tasks & $6 \times 2=12$ tasks \\
Boundary conditions & $+6 \mathrm{~h}$ ERA-interim; & $+1 \mathrm{~h}$ data from & $+3 \mathrm{~h}$ data \\
& $+3 \mathrm{~h} \mathrm{SST}$ from & CCLM; & from CCLM and \\
& TRIMNP (ERA-interim & $+3 \mathrm{~h}$ data from CICE; & TRIMNP; \\
& for none matching areas & + Climatological data from & + open lateral \\
& between the two domains); & FES2004 and LEVITUS94; & boundary \\
& $+3 \mathrm{~h}$ sea ice skin & + initial SST from NOAA & + initial SST \\
& temperature from CICE & & from NOAA \\
\hline
\end{tabular}

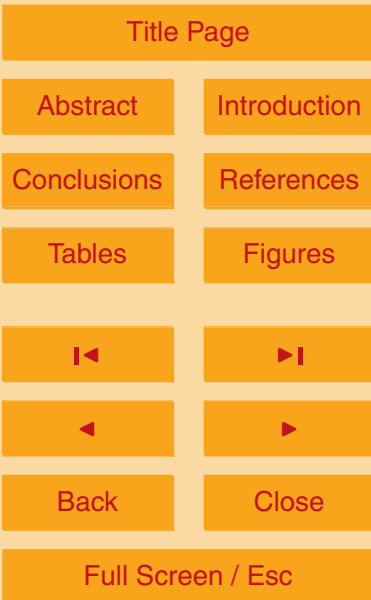

Printer-friendly Version

Interactive Discussion 


\section{GMDD}

5, 3261-3310, 2012

COSTRICE - three model online coupling using OASIS

H. T. M. Ho et al.

Table 2. List of the experiments.

\begin{tabular}{lll}
\hline EXPS & Strategy & Variables/heat flux transferred \\
\hline STERva & Uncoupled & Heat fluxes are calculated in TRIMNP \\
STERhf & Uncoupled & Heat fluxes are taken from CCLM \\
CPERAi & Coupled & Heat fluxes are provided by CCLM \\
\hline
\end{tabular}

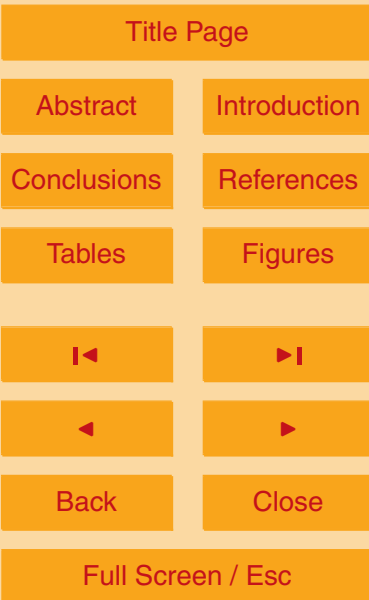

Printer-friendly Version

Interactive Discussion 
Table A1. List of acronyms.

\begin{tabular}{ll}
\hline Acronyms & Full name \\
\hline BALTEX & The Baltic Sea Experiment \\
CCLM & Consortium for Small-scale Modeling model in CLimate Mode \\
CERFACS & Centre Européen de Recherche et de Formation Avancée en Calcul Scientifique, \\
& France \\
CICE & Los Alamos sea ice model \\
COSTRICE & CCLM + TRIMNP + CICE \\
DKRZ & The German Climate Computing Center \\
ECMWF & European Centre for Medium-Range Weather Forecasts \\
ERA & ECMWF reanalysis data \\
GCM & Global climate model/General cirlation model \\
HAMSOM & The regional "Hamburg Shelf Ocean Model" of University of Hamburg, Germany \\
HELCOM & The Baltic Marine Environment Protection Commission or "Helsinki Commission" \\
HD & Hydrological Discharge (model) \\
HIRLAM & The high resolution limited area model of Sweden's Meteorological and \\
& Hydrological Institute \\
MITgcm & The general cirlation model of Massachusetts Institute of Technology, US \\
OASIS3 & The Ocean Amosphere Sea Ice Soil model version 3 of CERFACS, France \\
OISST & NOAA Optimum Interpolation Sea Surface Temperature (OISST) version 2 \\
RCM & Regional climate model \\
RegCM3 & Regional climate model version 3 of International Centre for Theoretical \\
& Physics (ICTP), Italy \\
REMO & Regional model of Max-Planck Institute for Meteorology, Germany \\
SST & Sea surface temperature \\
TRIMNP & The "Nested and Parallel" mode of the Tidal Residual and Intertidal Mudflat \\
& Simulations in 3 Dimensions model \\
\hline
\end{tabular}

COSTRICE - three model online coupling using OASIS

H. T. M. Ho et al.

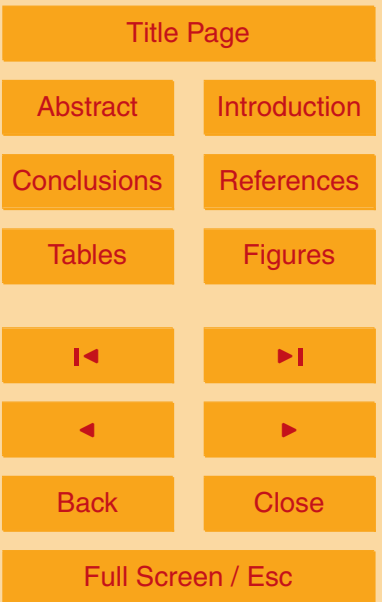

Printer-friendly Version

Interactive Discussion 
Table B1. An example of the source code changes of CCLM using some specific PSMILe calls of OASIS3.

\begin{tabular}{|c|c|c|}
\hline Source code changes & Stand-alone CCLM & Coupled CCLM \\
\hline $\begin{array}{l}\text { + Initialization: } \\
\text { (sub. init_environtment in "environt- } \\
\text { ment.f90") }\end{array}$ & $\begin{array}{l}! \text { - start }-\overline{C a l l} \text { MPI_INIT } \\
\text { icomm_world = } \\
\text { MPI_COMM_WORLD }\end{array}$ & $\begin{array}{l}!-\text { start }- \\
\text { Call MPI_INIT } \\
\text { Call prism_init_comp_proto }(\ldots) \\
\text { Call prism_get_localcomm_proto }(\ldots) \quad ! \rightarrow \mathrm{kl} \_ \text {_comm } \\
\text { icomm_world }= \\
\text { kl_comm }\end{array}$ \\
\hline + Local partition definition & $\mathrm{x}$ & $\begin{array}{l}\text { paral ( clim_strategy ) = clim_serial } \\
\text { paral ( clim_length })=\text { ie_tot *je_tot } \\
\text { paral ( clim_offset ) }=0 \\
\text { Call prism_def_partition_proto (id_part, paral, ierror ) } \\
\text { inodims }(1)=1 \text { ! rank of coupling field } \\
\text { inodims }(2)=1 \\
\text { ishape }(1)=1 ! \text { min index for the coupling field local dimension } \\
\text { ishape }(2)=\text { ie_tot *je_tot ! max index }\end{array}$ \\
\hline + Coupling field declaration & $\mathrm{x}$ & 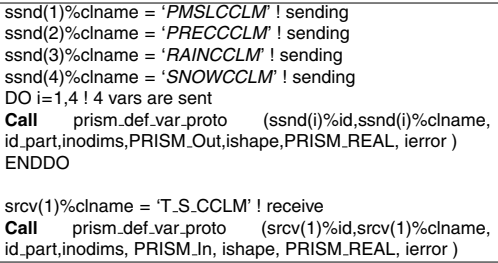 \\
\hline+ End of definition phase & $\mathrm{x}$ & Call prism_enddef_proto $(\ldots)$ \\
\hline $\begin{array}{l}\text { + Main program, time stepping loop: } \\
\text { - to get fields from OASIS }\end{array}$ & $\begin{array}{l}! \ldots . .=\mathrm{SST}(\mathrm{ib}: \mathrm{ie}, \mathrm{jb}: \mathrm{je}){ }^{*} \ldots . . \\
\ldots \ldots\end{array}$ & $\begin{array}{l}\text { DO istep = nstart, nstop } \\
\ldots \ldots \\
\text { Call prism_get_proto (..., istep, T_S_CCLM, ..) } \\
\text { Call distribute_filed (T___CCLM, ie_tot, je_tot, SST, ie,je) } \\
! \ldots .=\text { SST(ib:ie,jb:je) }{ }^{*} \ldots . . \\
\ldots \ldots\end{array}$ \\
\hline - to send fields to OASIS & 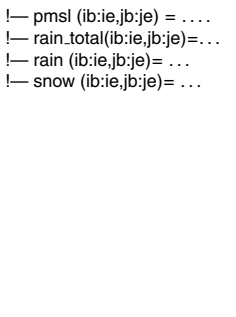 & 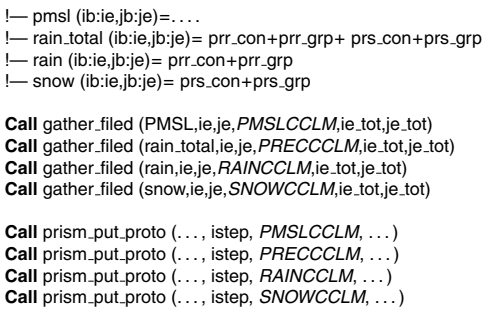 \\
\hline & ENDDO & ENDDO \\
\hline $\begin{array}{l}\text { + Termination: } \\
\text { (sub. final_environtment in "environt- } \\
\text { ment.f90") }\end{array}$ & $\begin{array}{l}!-\text { finish } \\
\text { Call MPI_FINALIZE }\end{array}$ & $\begin{array}{l}\text { Call prism_terminate_proto }(\ldots) \\
\text { Call MPI_FINALIZE }\end{array}$ \\
\hline
\end{tabular}

GMDD

5, 3261-3310, 2012

\section{COSTRICE - three model online coupling using OASIS}

H. T. M. Ho et al.

\section{Title Page}

\section{Abstract}

Introduction

Conclusions

References

Tables

Figures

14

$>$ I

4

Back

Close
Full Screen / Esc

Printer-friendly Version

Interactive Discussion 
Table C1. Passing SSTTRICE on the grid ocng of TRIMNP (after combined SST of TRIMNP with the sea ice temperature of $\mathrm{CICE}$ ) to the grid atmg of CCLM. The Lines are in the namcouple file. The explanation of each Line is given the shaded box below.

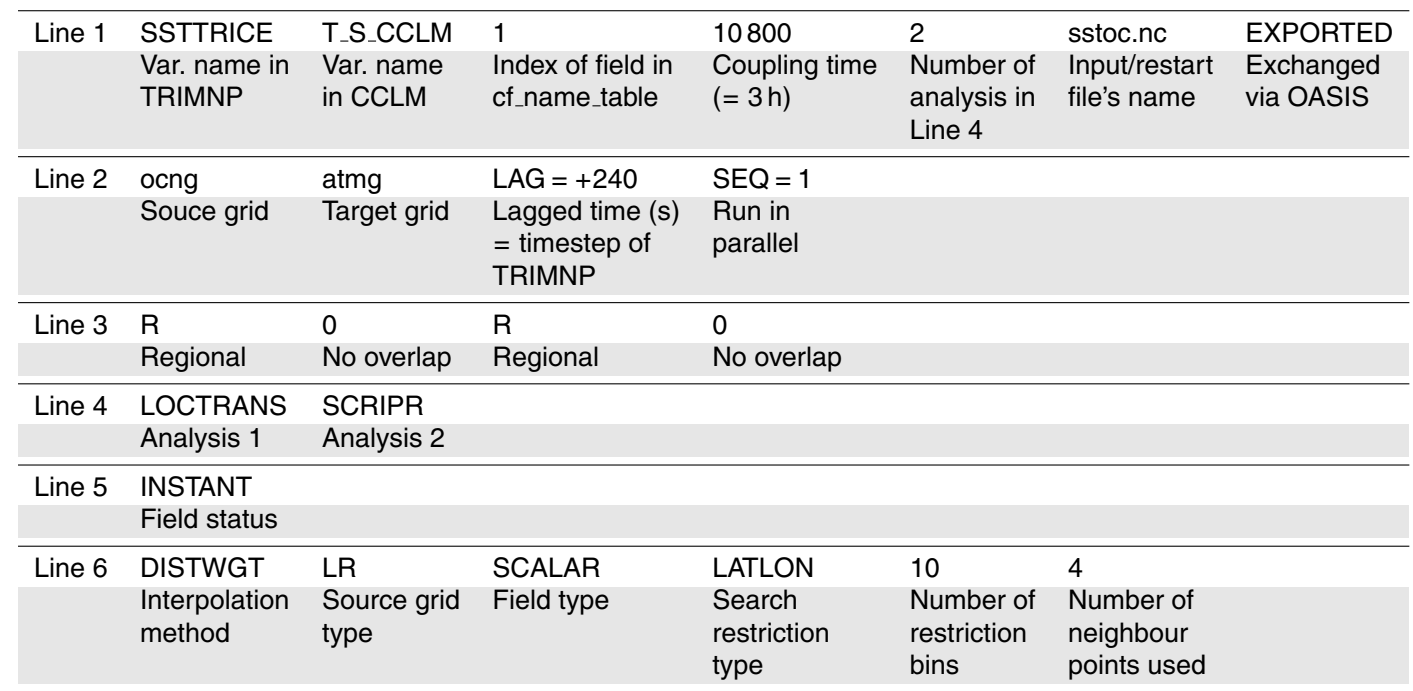

GMDD

$5,3261-3310,2012$

COSTRICE - three model online coupling using OASIS

H. T. M. Ho et al.

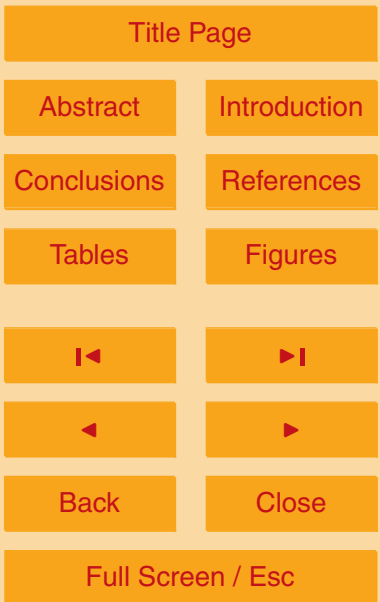

Printer-friendly Version

Interactive Discussion 
Table C2. Passing PMSL on the grid atmg of CCLM to the grid ocng of TRIMNP. Others detail are similar to Table $\mathrm{C} 1$.

\begin{tabular}{|c|c|c|c|c|c|c|c|}
\hline Line 1 & $\begin{array}{l}\text { PMSLCCLM } \\
\text { Var. name in } \\
\text { CCLM }\end{array}$ & $\begin{array}{l}\text { PMSLTRIM } \\
\text { Var. name } \\
\text { in TRIMNP }\end{array}$ & $\begin{array}{l}33 \\
\text { Index of field in } \\
\text { cf_name_table }\end{array}$ & $\begin{array}{l}3600 \\
\text { Coupling time } \\
(=1 \mathrm{~h})\end{array}$ & $\begin{array}{l}2 \\
\text { Number of } \\
\text { analysis in } \\
\text { Line } 4\end{array}$ & $\begin{array}{l}\text { atmin.nc } \\
\text { Input/restart } \\
\text { file's name }\end{array}$ & $\begin{array}{l}\text { EXPORTED } \\
\text { Exchanged } \\
\text { via OASIS }\end{array}$ \\
\hline \multirow[t]{2}{*}{ Line 2} & atmg & ocng & $\mathrm{LAG}=+300$ & $S E Q=1$ & & & \\
\hline & Souce grid & Target grid & $\begin{array}{l}\text { Lagged time (s) } \\
=\text { timestep of } \\
\text { CCLM }\end{array}$ & $\begin{array}{l}\text { Run in } \\
\text { parallel }\end{array}$ & & & \\
\hline \multirow[t]{2}{*}{ Line 3} & $\mathrm{R}$ & 0 & $\mathrm{R}$ & 0 & & & \\
\hline & Regional & No overlap & Regional & No overlap & & & \\
\hline \multirow[t]{2}{*}{ Line 4} & LOCTRANS & SCRIPR & & & & & \\
\hline & Analysis 1 & Analysis 2 & & & & & \\
\hline \multirow[t]{2}{*}{ Line 5} & INSTANT & & & & & & \\
\hline & Field status & & & & & & \\
\hline \multirow[t]{2}{*}{ Line 6} & DISTWGT & LR & SCALAR & LATLON & 10 & 4 & \\
\hline & $\begin{array}{l}\text { Interpolation } \\
\text { method }\end{array}$ & $\begin{array}{l}\text { Source grid } \\
\text { type }\end{array}$ & Field type & $\begin{array}{l}\text { Search } \\
\text { restriction } \\
\text { type }\end{array}$ & $\begin{array}{l}\text { Number of } \\
\text { restriction } \\
\text { bins }\end{array}$ & $\begin{array}{l}\text { Number of } \\
\text { neighbour } \\
\text { points used }\end{array}$ & \\
\hline
\end{tabular}

GMDD

$5,3261-3310,2012$

COSTRICE - three model online coupling using OASIS

H. T. M. Ho et al.

\section{Title Page}

\section{Abstract}

Introduction

Conclusions

References

Tables

Figures

14

$\rightarrow$ I

4

Back

Close

\section{Full Screen / Esc}

Printer-friendly Version

Interactive Discussion 


\section{COSMO-CLM}

\section{TRIMNP}

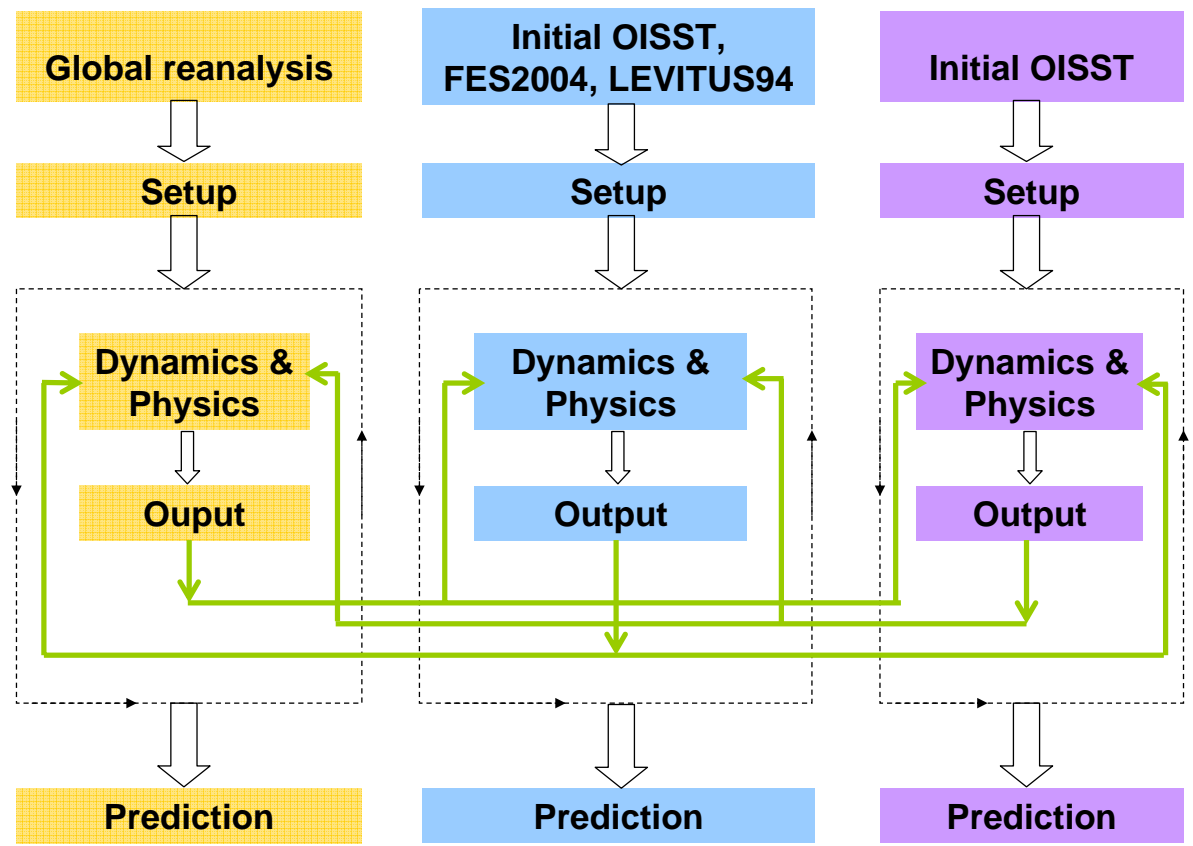

Fig. 1. Schematic of the coupled system COSTRICE. Dash boxes describe time loops in each component model. OASIS3 couples component models via green routes.

\section{GMDD}

$5,3261-3310,2012$

COSTRICE - three model online coupling using OASIS

H. T. M. Ho et al.

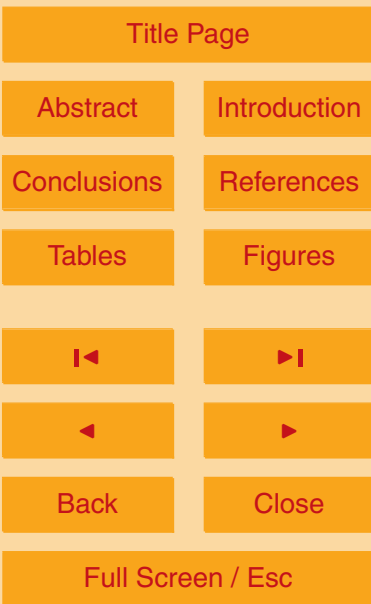

Printer-friendly Version

Interactive Discussion 


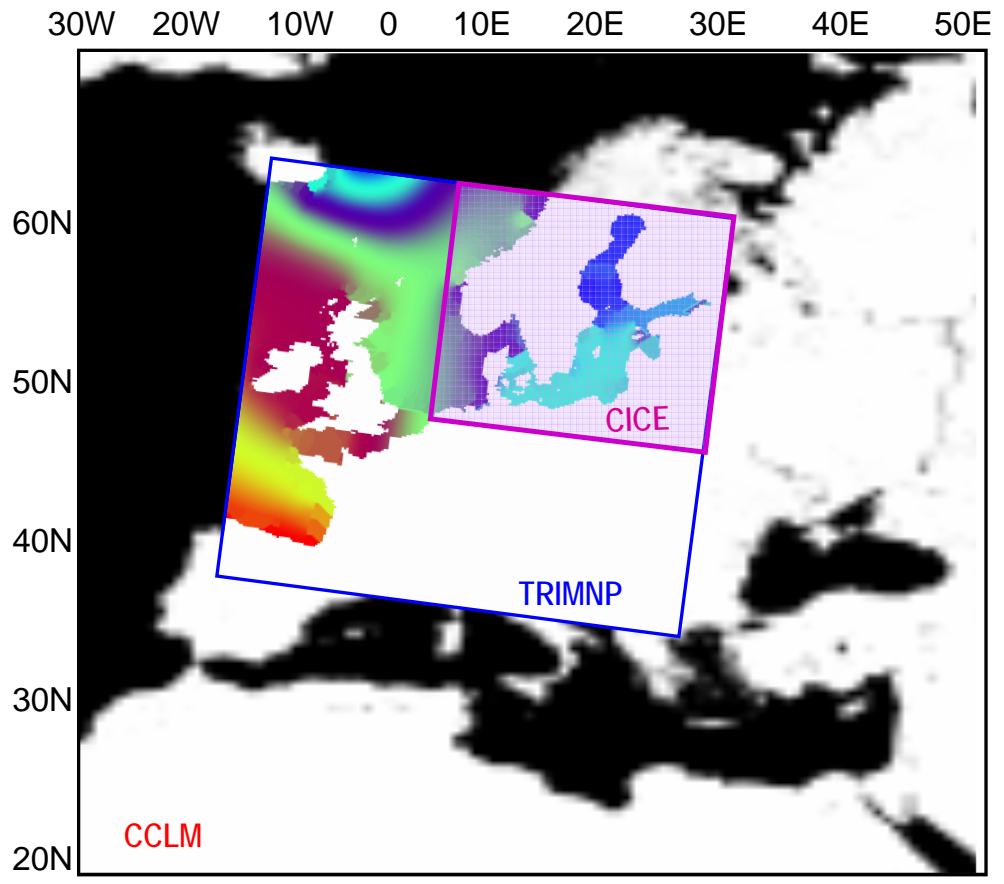

\section{GMDD}

5, 3261-3310, 2012

COSTRICE - three model online coupling using OASIS

H. T. M. Ho et al.

Title Page

Abstract

Conclusions

\section{Tables}

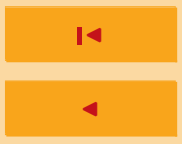

4

Back

Full Screen / Esc

Printer-friendly Version

Interactive Discussion 


\section{GMDD}

$5,3261-3310,2012$

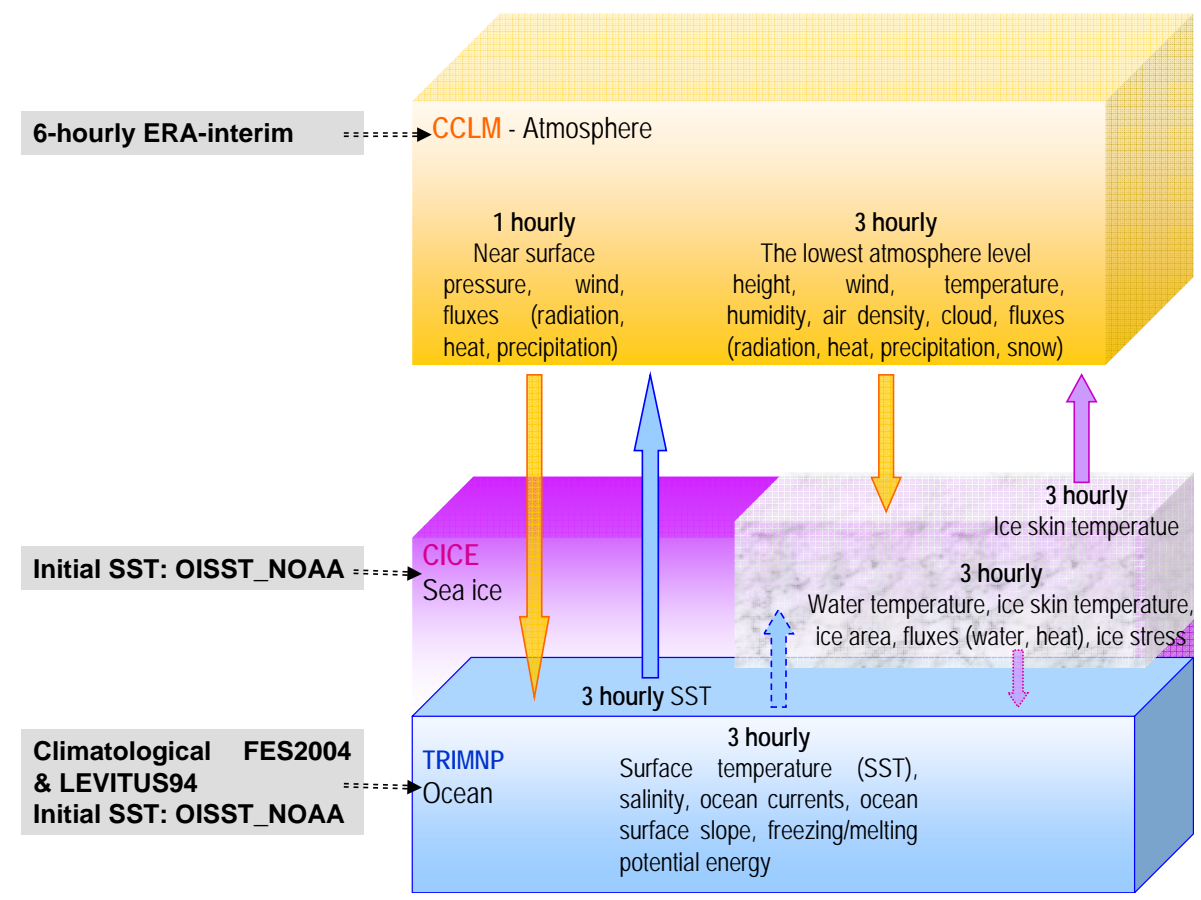

COSTRICE - three model online coupling using OASIS

H. T. M. Ho et al.

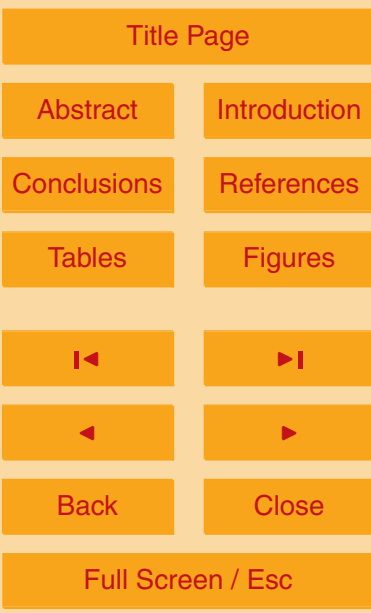

Fig. 3. A schematic diagram for two-way regional model coupling.

Printer-friendly Version

Interactive Discussion 


\section{GMDD}

$5,3261-3310,2012$

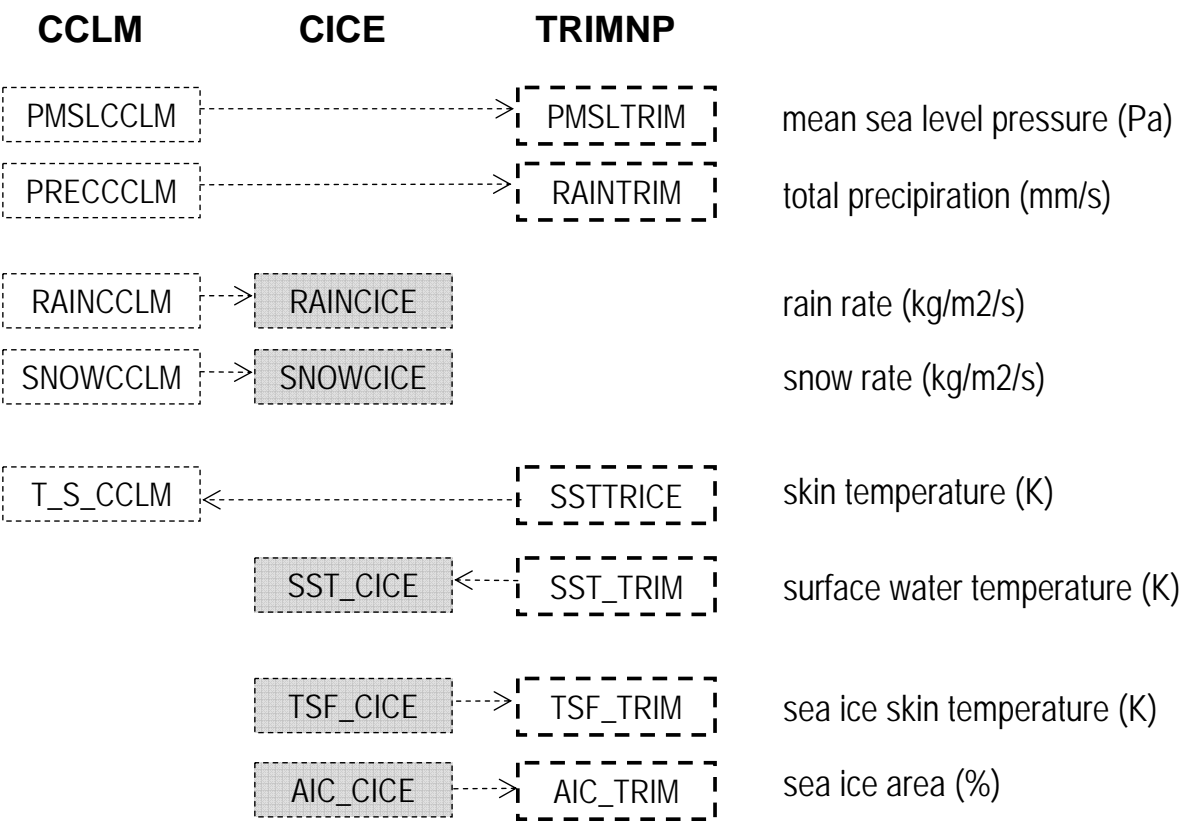

Fig. 4. An example of name of variables defined in the three models. Arrows display the direction of sending.

\section{COSTRICE - three model online coupling using OASIS}

H. T. M. Ho et al.

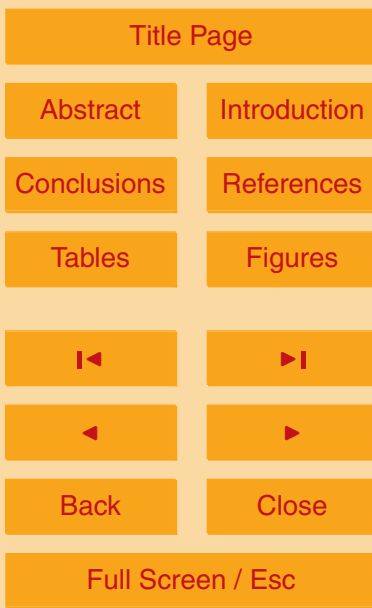

Printer-friendly Version

Interactive Discussion 


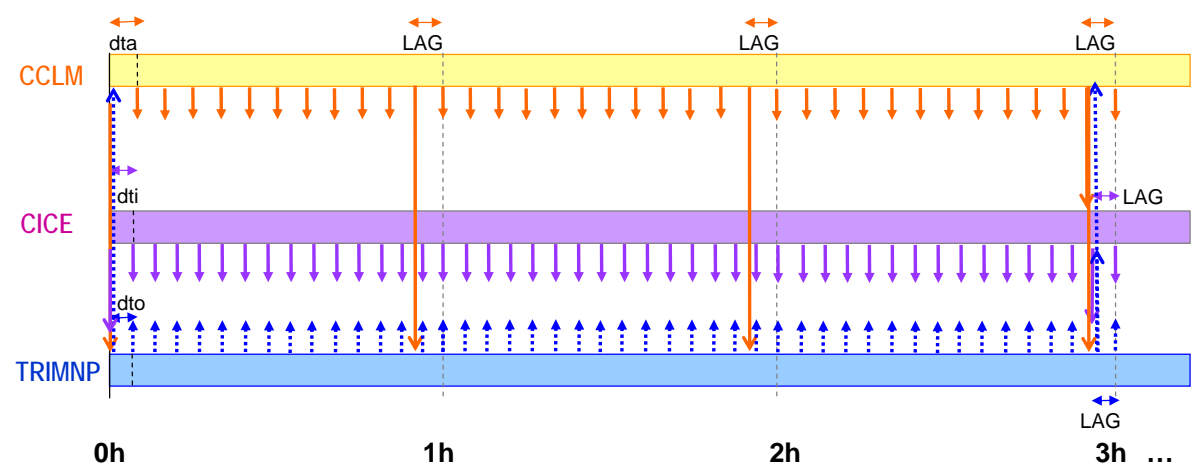

Fig. 5. A schematic diagram for online coupling process amongst the three component models. dta, dti, dto are running time steps of CCLM, CICE and TRIMNP, respectively. Coupling time step of CCLM to TRIMNP is $1 \mathrm{~h}$. Other coupling time steps are $3 \mathrm{~h}$. LAG is the lagged time before each coupling time step.

\section{GMDD}

$5,3261-3310,2012$

COSTRICE - three model online coupling using OASIS

H. T. M. Ho et al.

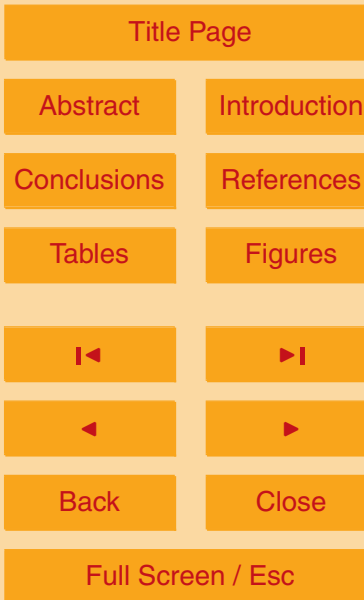

Printer-friendly Version

Interactive Discussion 


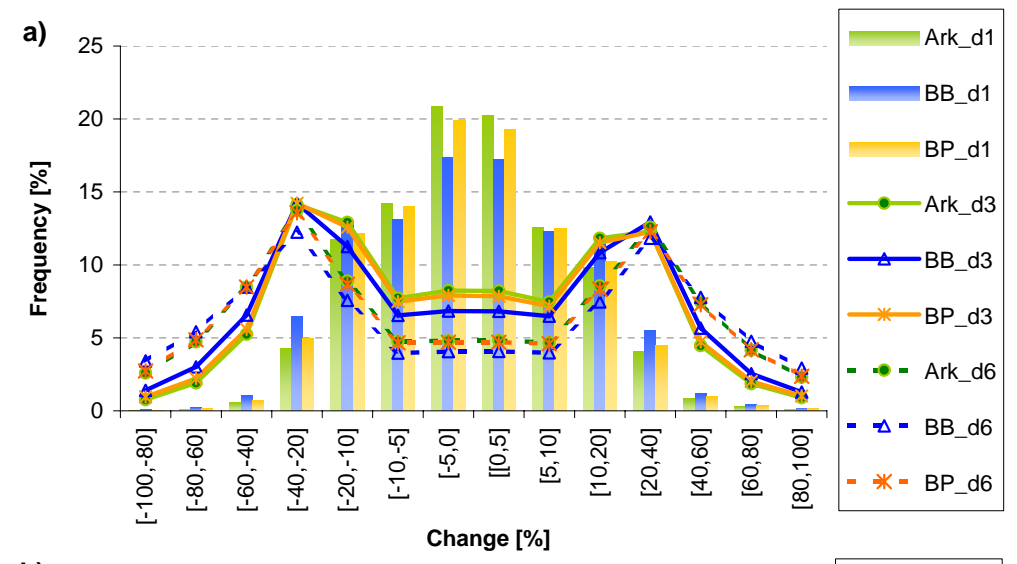

\section{GMDD}

$5,3261-3310,2012$

\section{COSTRICE - three} model online coupling using OASIS

H. T. M. Ho et al.
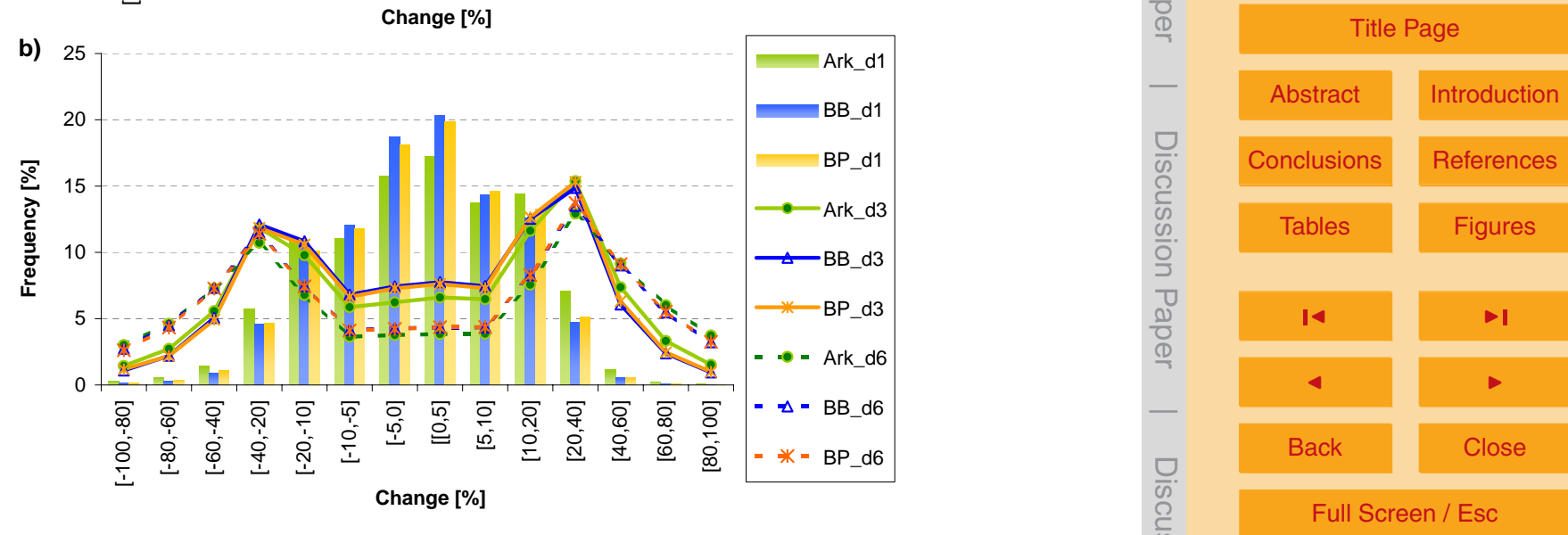

Fig. 6. Frequency (\%) of the 1-, 3- and 6-h changes (\%) of (a) U10M and (b) V10M in the uncoupled CCLM simulation from 1948-2010 over Arkona Sea (Ark), Bothnian Bay (BB) and Baltic Proper (BP).

Printer-friendly Version

Interactive Discussion 


\section{GMDD}

$5,3261-3310,2012$
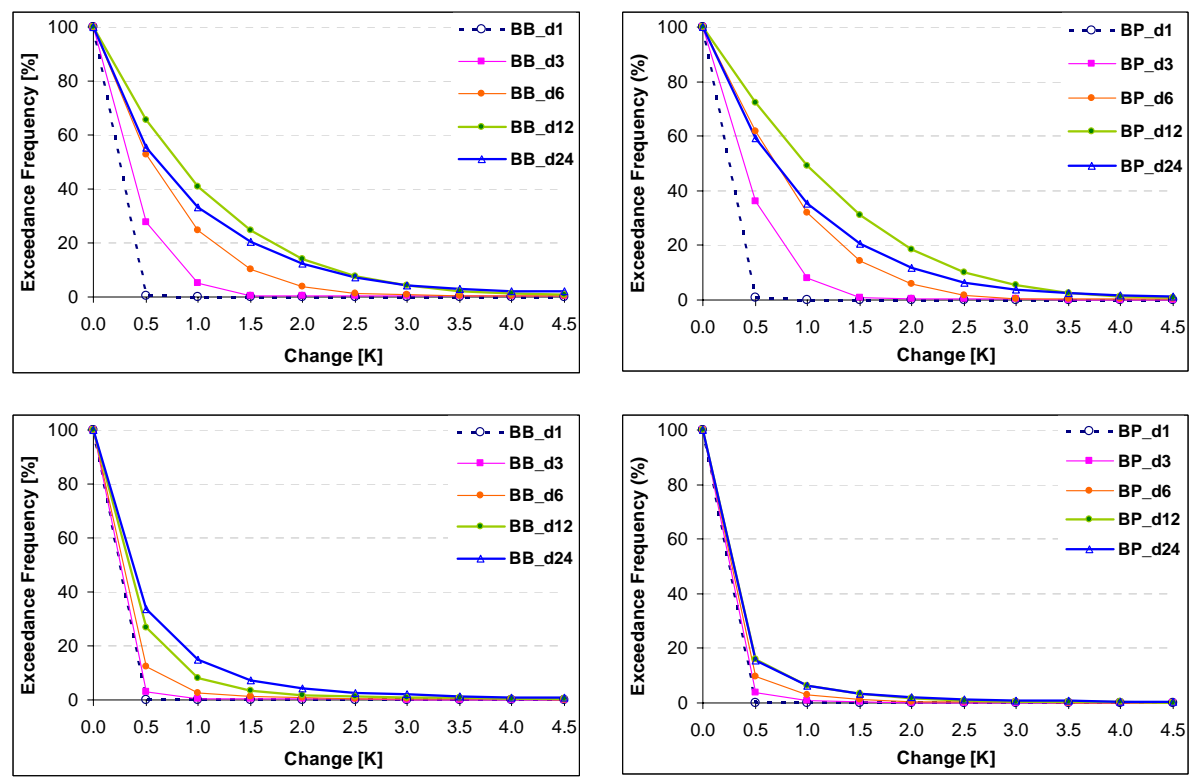

Fig. 7. Exceedance frequency (\%) of the 1-, 3-, 6-, 12- and 24-h changes (K) of SST in the uncoupled TRIMNP simulation from 1980-2007 over Bothnian Bay (BB, left) and Baltic Proper (BP, right) using data from May to September (top) and in remaining months of the year (bottom).

\section{COSTRICE - three model online coupling using OASIS}

H. T. M. Ho et al.

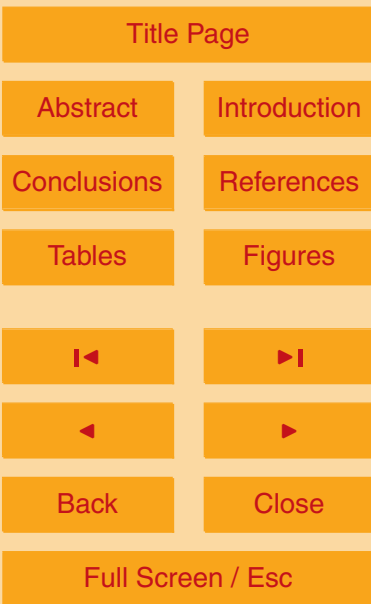

Printer-friendly Version

Interactive Discussion 


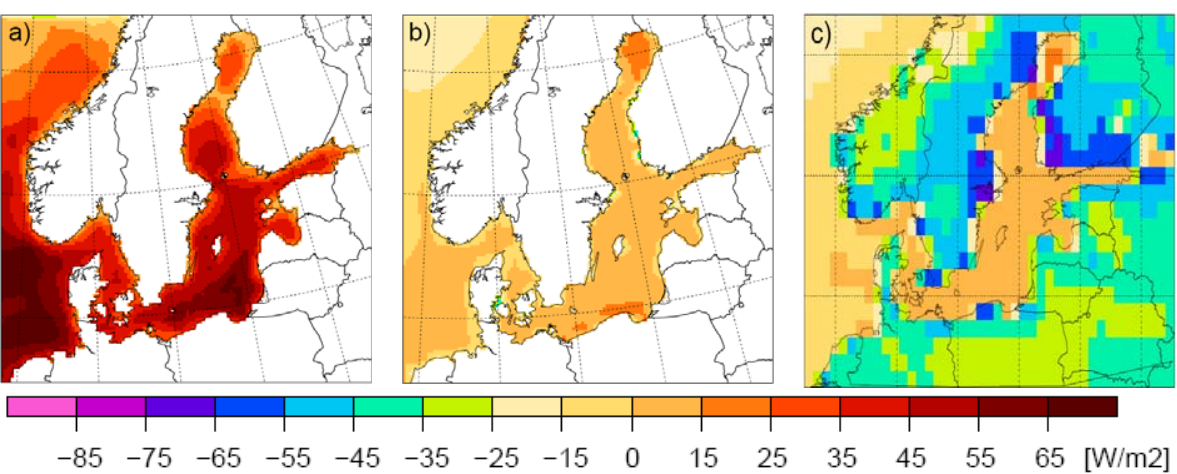

Fig. 8. The monthly averaged sensible heat flux $\left(\mathrm{Wm}^{-2}\right)$ simulated in (a) STERva, (b) STERhf and (c) ERA-interim data in May 1997. Downward flux has a positive value.

\section{GMDD}

$5,3261-3310,2012$

COSTRICE - three model online coupling using OASIS

H. T. M. Ho et al.

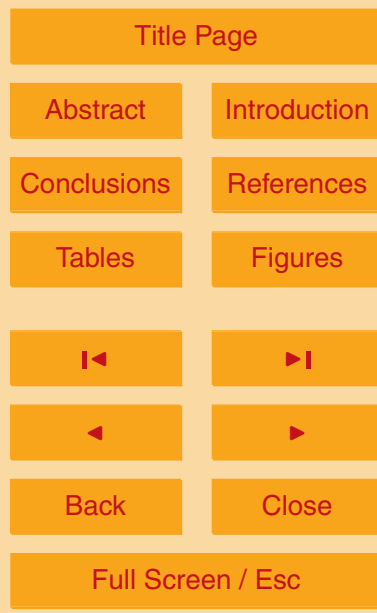

Printer-friendly Version

Interactive Discussion 


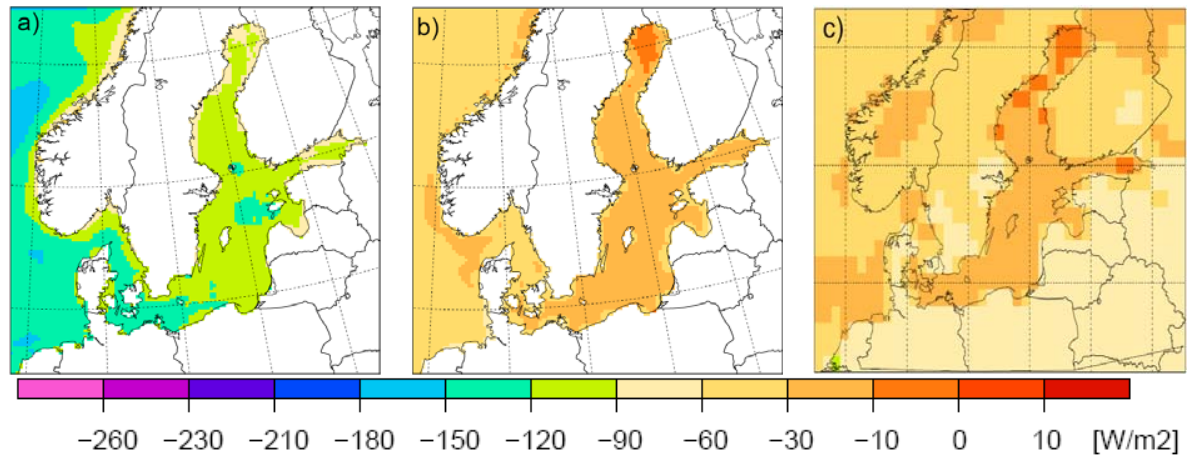

Fig. 9. Same as Fig. 8 but for the latent heat flux $\left(\mathrm{Wm}^{-2}\right)$.

\section{GMDD}

5, 3261-3310, 2012

COSTRICE - three model online coupling using OASIS

H. T. M. Ho et al.

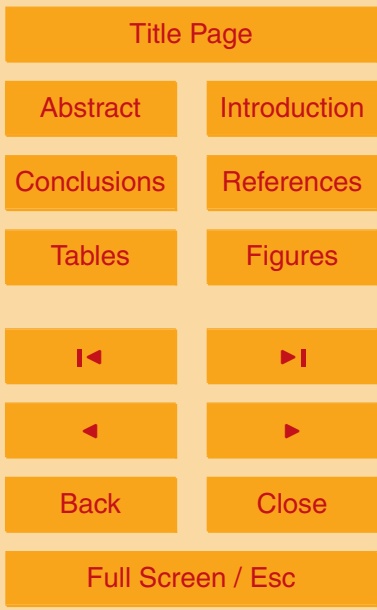

Printer-friendly Version

Interactive Discussion 


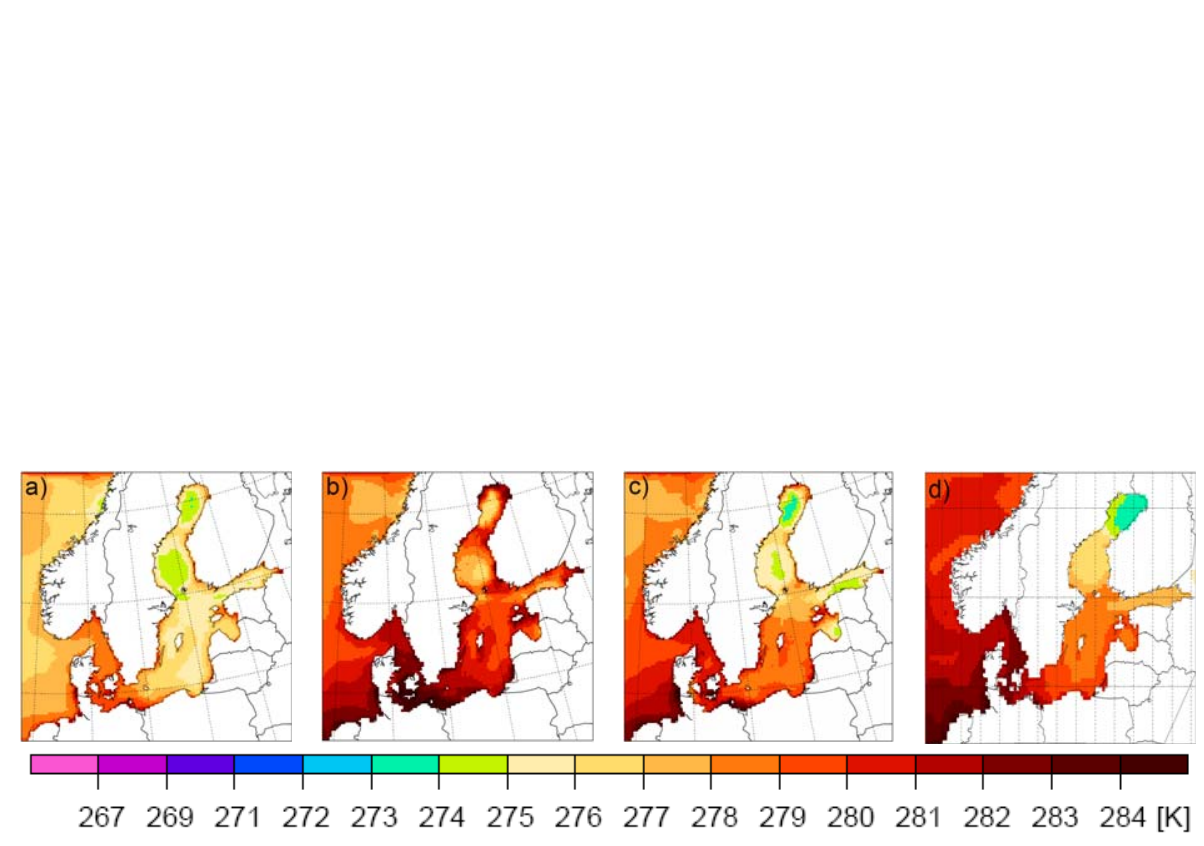

\section{GMDD}

5, 3261-3310, 2012

COSTRICE - three model online coupling using OASIS

H. T. M. Ho et al.

Fig. 10. The monthly averaged SST (K) simulated in (a) STERva, (b) STERhf, (c) CPERAi and (d) OISST in May 1997. 


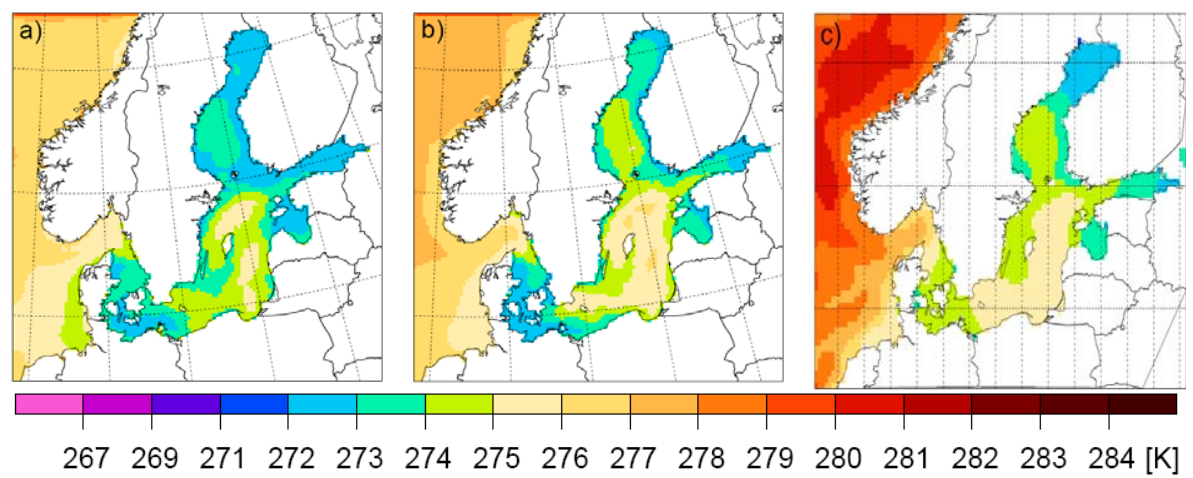

Fig. 11. The monthly averaged SST (K) simulated in (a) STERhf, (b) CPERAi, and (c) OISST in February 1997.

\section{GMDD}

5, 3261-3310, 2012

COSTRICE - three model online coupling using OASIS

H. T. M. Ho et al.

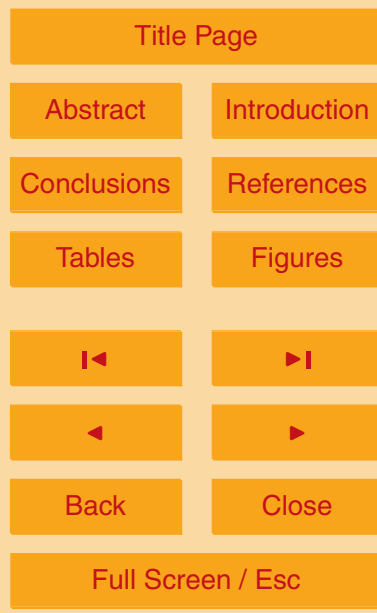

Printer-friendly Version

Interactive Discussion 


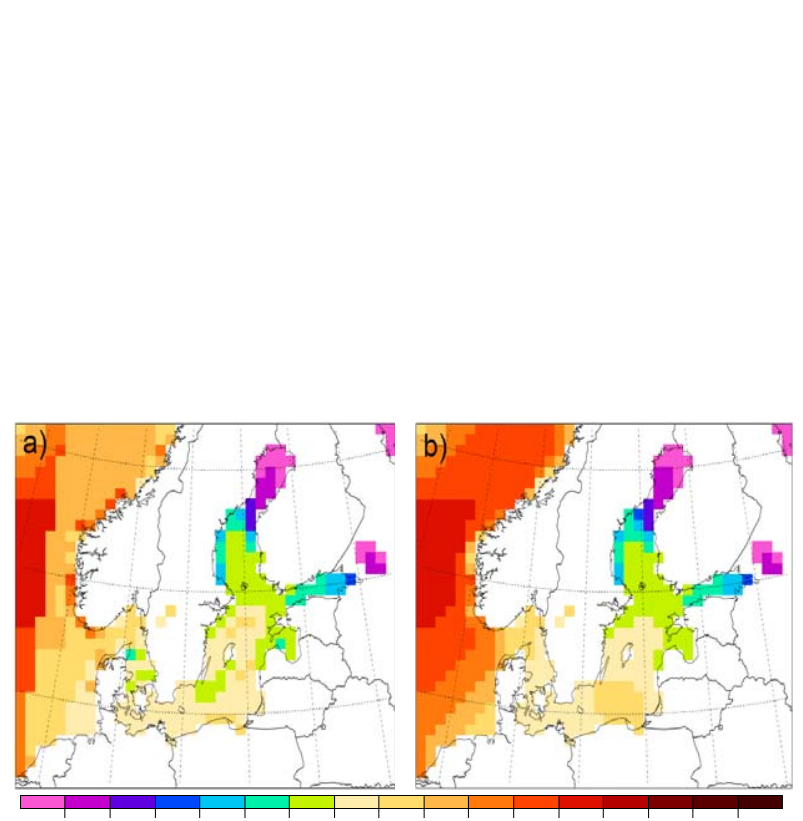

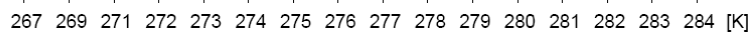

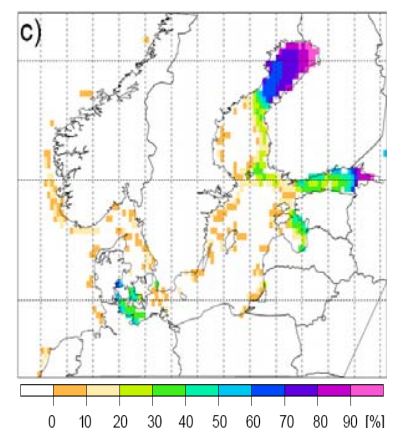

$\begin{array}{lllllllllll}0 & 10 & 20 & 30 & 40 & 50 & 60 & 70 & 80 & 90[\%]\end{array}$

Fig. 12. The monthly averaged skin temperature $(K)(a)$ simulated in CPERAi and (b) from ERAinterim data in February 1997; (c) the monthly averaged ice concentration (\%) from NOAA data in February 1997.

\section{GMDD}

$5,3261-3310,2012$

COSTRICE - three model online coupling using OASIS

H. T. M. Ho et al.

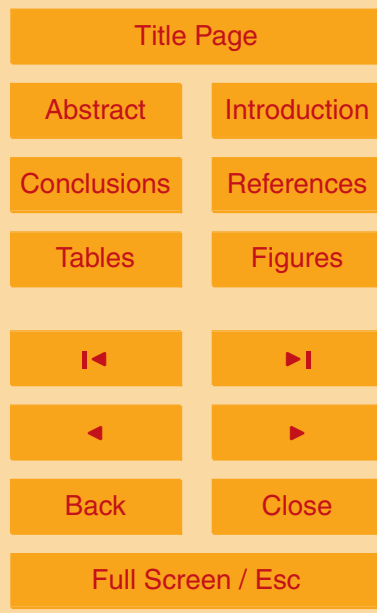

Printer-friendly Version

Interactive Discussion 

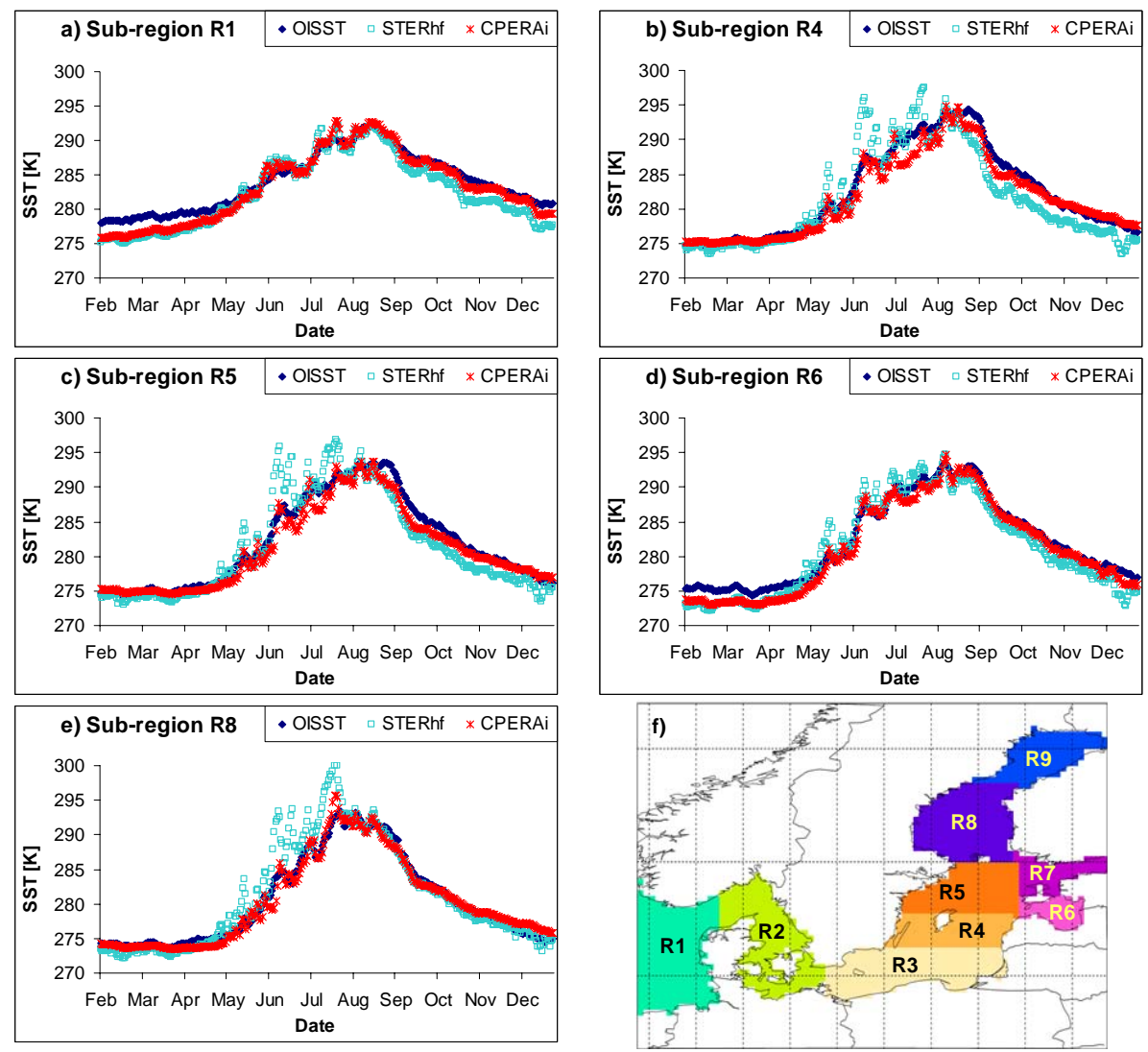

Fig. 13. The daily SST (K) of OISST, STERhf and CPERAi in time period of 1 February to 31 December 1997 averaged over the sub-regions R1, R4, R5, R6, R8 (a-e) in Baltic Sea and North Sea (f).

\section{GMDD}

$5,3261-3310,2012$

COSTRICE - three model online coupling using OASIS

H. T. M. Ho et al.

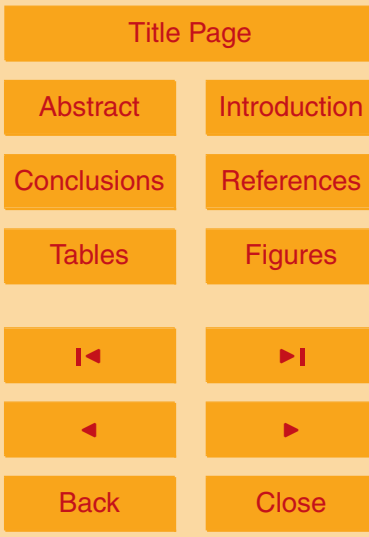

Full Screen / Esc

Printer-friendly Version

Interactive Discussion 